\title{
Experimental and numerical analysis of early age behavior in non-reinforced concrete
}

\author{
Thanh-Tung Nguyen ${ }^{\mathrm{a}}$, Michael Weiler ${ }^{\mathrm{a}}$, Danièle Waldmann ${ }^{\mathrm{a}}$ \\ ${ }^{a}$ University of Luxembourg, Laboratory of Solid Structures, \\ 6, Rue Richard Coudenhove-Kalergi, L-1359, Luxembourg
}

\begin{abstract}
An approach combining numerical simulations and experimental techniques is proposed to investigate the early-age properties of non-reinforced concrete. Both thermo-mechanical and fracture behaviors are studied, providing a deep insight into the hydration process. This work makes an important step in understanding the effects of hydration on the performance of cement-based materials. More specifically, in the first part, the shrinkage and fracture properties of a non-reinforced concrete have been experimentally considered, along with the characterization of several material parameters. The experimental results exhibit a high risk of early-age cracking for this kind of concrete. Especially, the fracture phenomena are complex, including multi-evolution-stages, initiation, propagation, stop-growing, and re-growing. In the second part, the computational modeling based on the phase field method of failure mechanism is applied to simulate the thermal, mechanical and fracture behavior due to early-age hydration. A detailed discussion on the identification of model/material parameters and the construction of numerical model including the boundary conditions is given. We provide the following comparison between predictions of the numerical simulation with the experimental observations. An excellent predictive capability of the computational model is noted. More importantly, this work demonstrates the performance of the proposed approach, which requires only a few tests to identify the model inputs. Most of the chemo-thermal parameters can be theoretically determined based on the concrete mix and the chemical/mineral compositions of the cement.
\end{abstract}

Keywords: Early-age cracking, Crack propagation, Phase field model, Non-reinforced concrete, Multi-physics

\section{Introduction}

Plain and non-reinforced concrete is very common in infrastructure engineering, e.g., dams, slabs, airfields, or most screeds for domestic use. However, one of the most significant disadvantages of this concrete type is its sensibility with the early-age cracking due to the cement hydration and shrinkage. Hence, predicting the material performance regarding the strength due to earlyage cracking is highly required for the non-reinforced concrete in terms of key engineering application.

The early-age behavior of concrete is an extremely complex multi-physics problem, since the change of mechanical properties is fast and largely dependent on the physical and chemical processes at the different scale, ranging from the atomic level to macroscopic scale [1, 2]. The evaluation of thermal-mechanics and cracking in the concrete structure at young age often requires considering a so-called multi-physics problem of hydration process including many aspects such as chemical, thermal, mechanical, environmental, creep and shrinkage effects 3 . Hence, it remains challenging in both experimental and numerical investigations.

The early-age behavior of cement-based materials has been experimentally studied for decades. Several signifi-

\footnotetext{
Email address: thanh-tung.nguyen@uni.lu (Thanh-Tung Nguyen )

cant contributions in this area can be found, e.g., in 4, where the author developed a restrained shrinkage test methodology to characterize the early-age mechanical behaviors; Kolver et al. [5 and Østergaard et al. [6] studied the tensile creep of concrete at early-age; or another interesting work proposed by Lura et al. 7 to investigate the effects of curing temperature and type of cement on the shrinkage properties. The phenomena of autogenous shrinkage induced cracking are considered in [8] for high-performance concrete, in [9] for slag cement concretes, and in [10 13] for fiber reinforced concrete. More recently, the research contribution in this field often focuses on early-age hygro-thermo-chemo-mechanical behaviors [14 22]. The state-of-the-art numerical models studying early-age behavior in concrete is mainly based on the hygro-thermo-chemo-mechanical coupled framework [23 27]. In the same context, the assessment of cracking risk is also considered, e.g., in de Borst and Van den Boogaard [28] and De Schutter [29] by using smeared-crack modeling; or by crack band model in Bažant et al. 30. Several other numerical techniques in this field can be listed as a Microplane model in 31, the lattice approach in 32, or damage model based on the Mazars's damage criterion [33] in 34. However, due to the complexity of the problem, the accuracy of the numerical prediction for early-age cracking is still an open question. The aforementioned works are only able 
to provide either a qualitative comparison or stochastic comparison of crack propagation phenomena induced by cement hydration [21, 22. Another drawback of the computational models in literature is their lack of efficiency, which often needs a large number of tests to characterize the model inputs [21, 34]. A performance numerical framework is able to accurately predict the early-age cracking in concrete, such as, crack initiation, crack evolution (crack length) in time and crack morphology is not available so far.

The objective of the present work is precisely to tackle the difficult issue of developing a robust approach, which is able to accurately predict the performance of concrete materials without requiring too many experimental testings for model inputs. We focus here on the early-age behavior of an unreinforced concrete C20/25 (a ready normal strength class). Both experimental methodologies and numerical approaches will be used. In the experimental part, the thermal and shrinkage properties are investigated by using the semi-adiabatic temperature rise test [35] and a special experimental set-up of shrinkage drain 36 38. The assessment of fracture due to early-age hydration for the studied material is then conducted. A critical working condition is proposed to imply several critical zones with a high risk of cracking, which is similar to those introduced in [39, 40. The computational method based on the coupled multi-physics model in the phase field framework 41, 42, is adopted in the numerical part. This model is based on the chemothermo-mechanical coupling scheme presented in [25, 43, where the effects of both basic and transient thermal creeps are thus considered and integrated into the versatile phase field model in the framework of smeared crack models presented by Marigo and Francfort in 44, Miehe et al. 45. A detailed discussion on the identification of the model inputs by using both experimental and theoretical methods is provided. We show that most of the model parameters can be theoretically determined based on the concrete mix and the chemical/mineral compositions of the cement. Only a few tests are needed to identify mechanical and thermal parameters, demonstrating the potential of the proposed approach for the real problem in civil engineering application. Comparisons between numerical predictions of shrinkage/fracture behaviors and experimental observations are performed. Especially, we provide a deep insight into the effects of creeps and interaction between different fracture zone on the global behavior of the concrete structure.

The paper is structured as follows: in Section 2, a study of mechanical properties and shrinkage/fracture behavior of the modeled material concrete C20/25 using experimental methodologies is derived. A brief description of the numerical model is presented in Section 3. The identification procedure of material and model parameters is described in Section 4. Finally, a comparison between the predictions of the numerical model and the experimental observations is provided in Section 5 . In the same section, we also detail the construction of the numerical model based on the experimental set-up.
Some major conclusions drawn from the study are given in the last section.

\section{Experiment}

\subsection{Material}

The concrete used in this study is a normal strength class C20/25. It is commonly used for the reinforced foundations, internal floor slabs, and many other infrastructure components as a non-reinforced concrete, such as dams, slabs, screeds, etc. Hence a detailed investigation of the risk of fracture for this material is strongly needed.

An overview of the present mix is described in Table 1. The CEM II A-LL 42.5 N-type cement (Portland cement) is used, according to LST EN 197-1: 2011 requirements, and its mineral compositions are provided in Table 2 Note that this mix is designed to screeds, according to the standard DIN 18560-1 in Germany. The maximum of aggregate size $16 \mathrm{~mm}$ satisfies the condition of three times smaller than the sample size.

Several samples have been manufactured to characterize the mechanical, thermal/shrinkage and fracture properties of the modeled material. The curious reader is referred to [37. for a detailed description of the experimental procedures.

\subsection{Mechanical properties}

The experiment in this section aims to characterize the mechanical properties of the investigated non-reinforced concrete, such as E-modulus, tensile/compressive strength, and critical fracture energy $g_{c}$. These material parameters will also be used as the inputs for the numerical models. The detailed descriptions for each test are depicted in Fig. 1. Four specimen-types have been manufactured corresponding to four different material property tests:

(i) The cylindrical sample with a diameter of $150 \mathrm{~mm}$, a height of $300 \mathrm{~mm}$, is manufactured to determine Young's modulus, see Fig. 11(a).

(ii) The specific I-shaped specimen with a total length of $500 \mathrm{~mm}$, a width at the ends of the specimen of $100 \mathrm{~mm}$, and a constant cross-section of $50 \mathrm{~mm} \times 50 \mathrm{~mm}$ at the middle edge, is used to determine the tensile strength, see Fig. 1(b). Note that, this test is performed with the use of a special device discussed in the works of [46, 47]. These tools allowed us to realize the tests at the very early-age after casting.

(iii) The cubic sample with a dimension $150 \mathrm{~mm} \times$ $150 \mathrm{~mm} \times 150 \mathrm{~mm}$ is adopted for the compressive strength test, see Fig. 11(c).

(iv) The pre-notched beam with a dimension of $700 \mathrm{~mm}$ $\times 150 \mathrm{~mm} \times 150 \mathrm{~mm}$ and the notch length of $15 \mathrm{~mm}$ is used for the determination of the fracture resistance $g_{c}$, as sketched in Fig. 11(d). 
Table 1: Description of the present concrete mix C20/25, unit is $\mathrm{kg} / \mathrm{m}^{3}$.

\begin{tabular}{llllll}
\hline Rhine Sand & Gravel 2/8 & Gravel 8/16 & CEM II/A LL 42.5 N & Water & unit \\
\hline 671.7 & 218.5 & 924.5 & 300.0 & 196.0 & {$\left[\mathrm{~kg} / \mathrm{m}^{3}\right]$} \\
\hline
\end{tabular}

Table 2: Mineral compositions of the cement CEM II A-LL $42.5 \mathrm{~N}$, unit is in \%.

\begin{tabular}{lllllllllll}
\hline Phase & $\mathrm{C}_{2} \mathrm{~S}$ & $\mathrm{C}_{3} \mathrm{~S}$ & $\mathrm{C}_{3} \mathrm{~A}$ & $\mathrm{C}_{4} \mathrm{AF}$ & $\mathrm{MgO}$ & $\mathrm{CaCO}_{3}$ & $\mathrm{CaSO}_{4}$ & $\mathrm{~K}_{2} \mathrm{SO}_{4}$ & Others & unit \\
\hline Composition & 7.44 & 55.30 & 6.25 & 10.55 & 3.15 & 11.15 & 2.19 & 2.91 & 1.06 & {$[\%]$} \\
\hline
\end{tabular}

The manufactured specimens are all stored in the climate chamber at $20^{\circ} \mathrm{C}$ and $50 \%$ relative humidity, see 37] for more practical information on the set-up of the mechanical testing.

The mechanical tests have been conducted at 48 hours, 168 hours, and 672 hours after casting, except the tensile strength tests which were also performed at the age of 8 hours. For each property, we have made three tests, the obtained average values are given in Fig. 2, The Young's modulus at the end of the hydration process is about $E_{\infty}=30 \mathrm{GPa}$. The final compressive strength and the final tensile strength are $\sigma_{c, \infty}=22.5 \mathrm{MPa}$, and $\sigma_{c t, \infty}=2.3 \mathrm{MPa}$, respectively ${ }^{1}$. The three-point bending flexural test is performed only once at the age of 90 days after casting to evaluate the fracture energy, here we obtained $g_{c, \infty}=164.5 \mathrm{~N} / \mathrm{m}$. These values are comparable to the concrete design properties according to EN1992-1-1.

\subsection{Thermal and shrinkage properties}

Heat liberation is one of the most important characters of the cement hydration reactions, which often occurs within the first days after concrete casting. The heat evolution, which induces the strain development (mostly in tension), will provide the early-age thermal stresses. These phenomena can result in the loss of material resistance, such as the initiation/propagation of cracks, which strongly affects the durability of materials and structures [3. In this study, in order to get a deep insight into this chemo-thermo-mechanical behavior, the generation of hydration heat has been quantified using a specific experimental set-up following [35], as described in Fig. 3(c). A cubic sample with the dimensions $150 \mathrm{~mm} \times 150 \mathrm{~mm} \times 150 \mathrm{~mm}$ is put in the polystyrene box (thickness of $50 \mathrm{~mm}$ ) together with a heat flux sensor. Then, the whole testing system is stored in the climate chamber at $20^{\circ} \mathrm{C}$ and $50 \%$ relative humidity. The observed thermal behaviors are plotted in Fig. 4. where we also provided the comparison with the predictions of KINTEMP/KINFEST softwar ${ }^{2}$ The maximal temperature is $\approx 38^{\circ} \mathrm{C}$, reaching at the

\footnotetext{
${ }^{1}$ The final values of mechanical properties are characterized by performing the tests on the specimens with age more than one year.

${ }^{2}$ KINTEMP/KINFEST software has been developed by Prof Dr Gebauer. It is currently distributed by COBET Software company in Germany. First practical applications were published by Oecknick [48, and by Weise 49]. KINTEMP stands for kinematic temperature evolution and KINFEST for kinematic strength
}

concrete age of 18 hours, corresponding to the accelerated period of hydration reactions. The quick raising of hydration heat is also captured in this period. The KINTEMP/KINFEST software is here giving a good prediction compared to the experimental measurements.

Parallel to the study of the heat generation, we also investigate the shrinkage property of concrete, which has been recognized as one of the key aspects of the early-age behaviors [1. The shrinkage of concrete C20/25 is characterized via an experimental setup using the shrinkage drain 36 38, see Fig. 4(a). The shrinkage drain has the following dimensions: $1000 \times 100 \times 60 \mathrm{~mm}^{3}$. A neoprene layer was inserted to reduce sliding contact between concrete and steel drain. More specifically, the goal of this test is to access the autogenous shrinkage strain. Therefore, the moisture exchange with the ambient medium was prevented by means of a plastic foil, which entirely covers the whole specimen for the period from casting, up-to 28 days. Then, the specimen surfaces are kept free for drying shrinkage within the period $t>28$ days. The concrete sample is fixed in the drain by the steel hooks, whereby one side of the shrinkage drain is movable. The movable end of the shrinkage drain is in touch with a displacement transducer which records all displacement within a range of $2 \mathrm{~mm}$, as described in Fig. 4(b). This set-up ensures a constant measuring during the entire period of the test. Note that the measurement device was activated right after putting concrete into the mold, and the measured strain is set to zero at that moment. In another word, we assume that the shrinkage strain is equal to zero just after casting. The whole system of shrinkage drains was stored in a room, in which temperature and humidity were recorded during the entire test period, as depicted in Fig. 5(a).

The development of shrinkage strain is depicted in Fig. 5(b) for 84 days. The C20/25 concrete exhibits a great shrinkage strain, which is about $50 \mu \mathrm{m} / \mathrm{m}$ within two days after casting. At this moment the material strength is still low $\left(E \approx 15 \mathrm{GPa}, \sigma_{c} \approx 8 \mathrm{MPa}\right.$, and

development. The software is able to predict evolving material properties of various concrete mixtures with various boundary conditions. A tremendous high number of experimental tests which served as basis were collected for the development of the software. KINTEMP/KINFEST is able to estimate the temperature development caused by hydration heat and the strength development for each single point in the structure whereas the composition of the concrete mixture, the boundary conditions such as the fresh concrete temperature, the transition conditions (type of form-work; environmental temperature) and the geometry of structure are taken into account. 


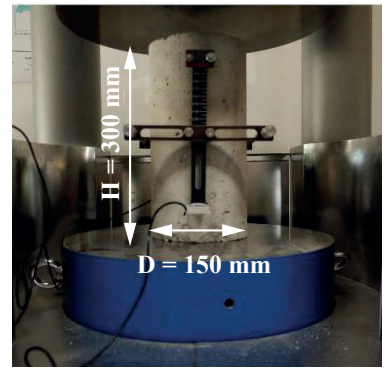

(a) Young's modulus test

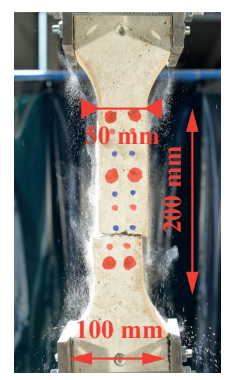

(b) Tensile strength test

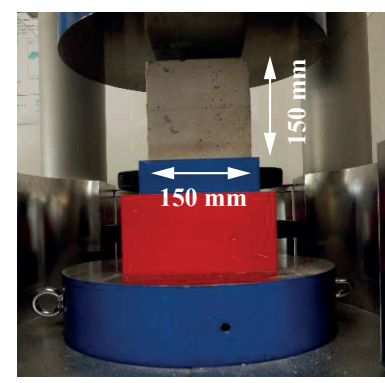

(c) Compressive strength test

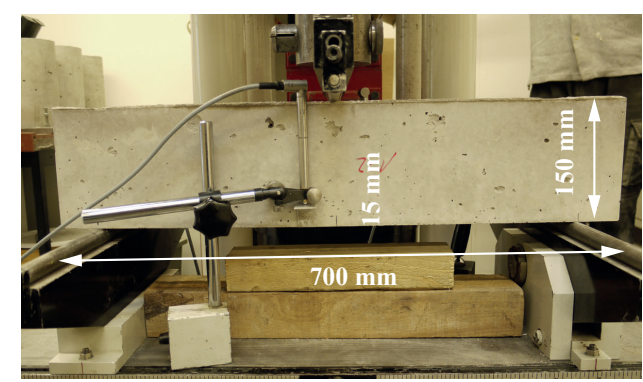

(d) Three-points bending test

Figure 1: Description of the experimental set-ups to characterize the mechanical properties.

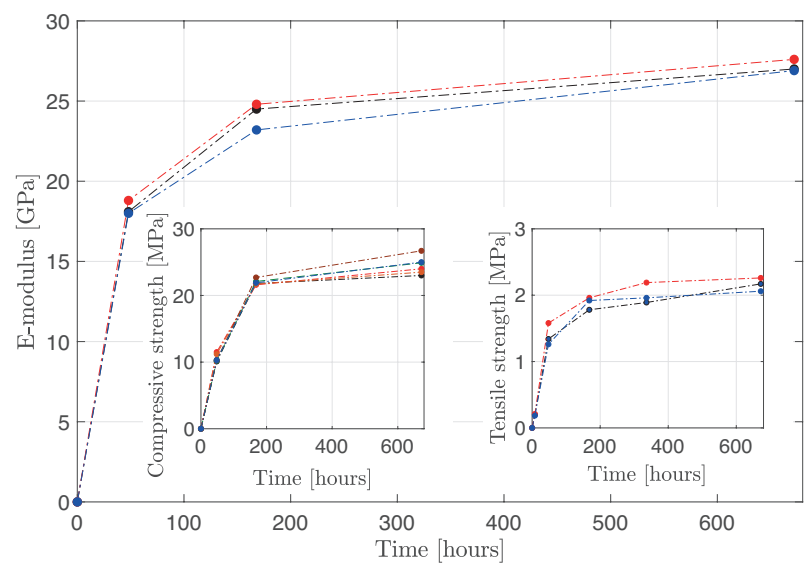

Figure 2: Experimental results of the evolution of material strength during the hardening process.

(a) Overview of the experimental set-up for measurements of shrinkage properties

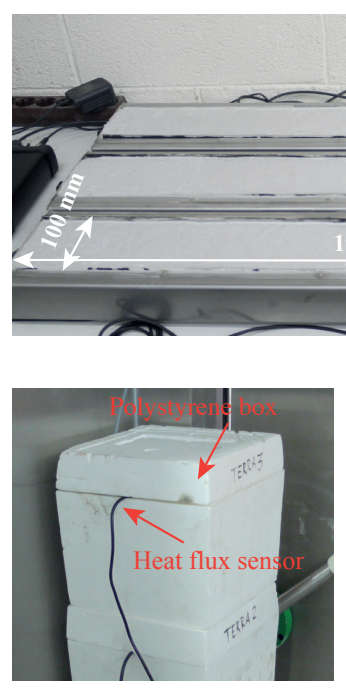

(c) Experimental set-up for measurements of hydration heat

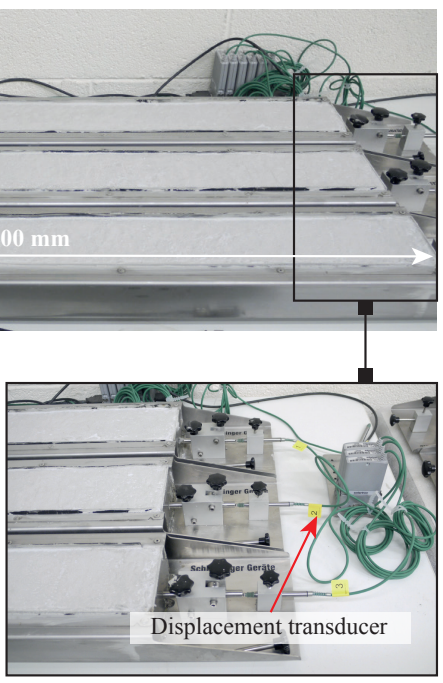

(b) Zoom on the measurement tools
Figure 3: Description of the experimental set-ups to investigate the thermal/shrinkage properties.

$\sigma_{c t} \approx 1 \mathrm{MPa}$ ). Therefore, if the structure is subjected to a critical working condition, the stress development will be occurred and will induce a high risk of premature cracking 3,28 . The evolution of shrinkage strain presents a stable part within the period [21 - 28] days,

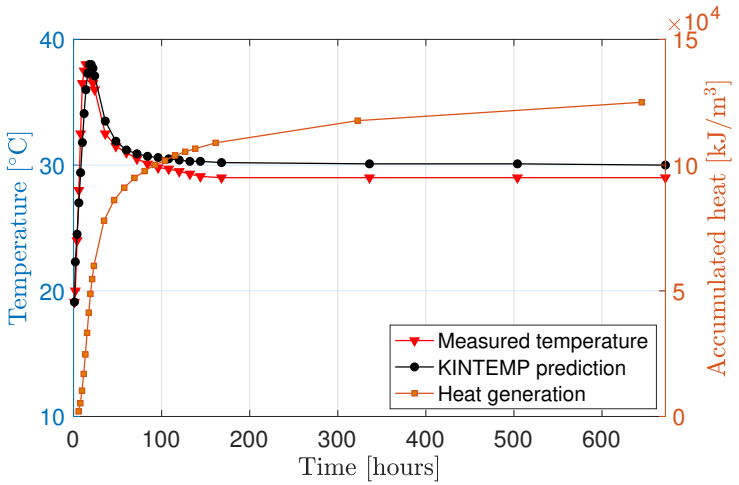

Figure 4: Experimental observation of accumulated heat release and temperature evolution.

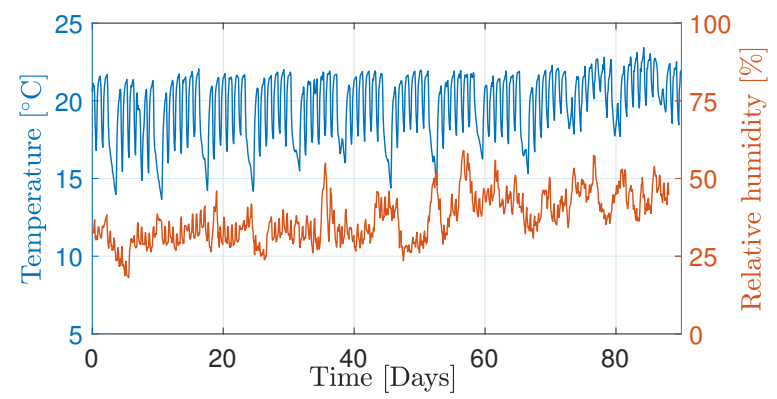

(a) Evolution of room temperature and relative humidity during the whole testing period

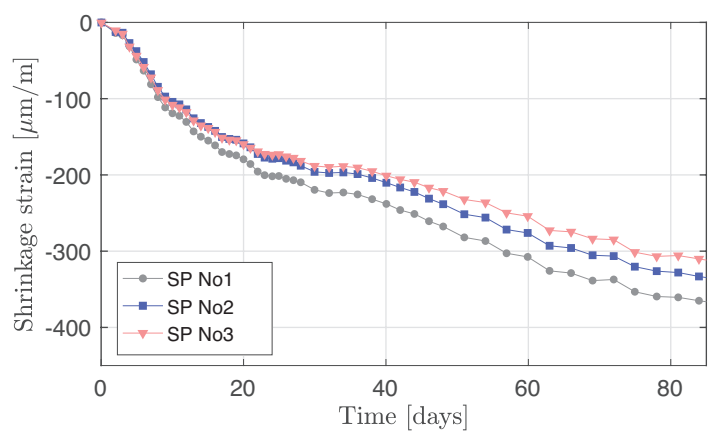

(b) Development of shrinkage strain of concrete C20/25 in the real environment conditions

Figure 5: Experimental study of the shrinkage process of the non-reinforced concrete.

which is related to the stabilization (finalization) of autogenous shrinkage behavior. The total measured 
shrinkage strain (including the drying shrinkage) is close to $320 \mu \mathrm{m} / \mathrm{m}$ at the end of the analyzed process. A small difference of shrinkage strain among three samples is noted. This variation could be related to several reasons, such as, the variation of humidity of aggregates, inhomogeneity of fresh concrete, and also distribution of aggregates. It should also be mentioned that the shrinkage process and thus, the hardening process were not completed when the data acquisition was stopped.

\subsection{Fracture assessment of the non-reinforced concrete material in a critical working condition}

The main objective of this part is devoted to evaluating the risk of cracking induced by early-age hydration in non-reinforced concrete. The choice of a specific specimen (geometry, dimensions), and specific boundary conditions are discussed in [37]. In general, this choice will provide a critical working condition, in which the damage and fracture can occur. The detailed description of the investigated system is sketched in Fig. 6, which is similar to the one proposed in [39, 40]. The H-shaped specimen with bracing of the central part by stiff steel tubes arranged symmetrically and parallel to the long sides of the middle part is considered. This geometry presents a reduction of the cross section at the middle part and a sharp increase of the geometry at the extremities. This implies the critical zones at four vertices with a high risk of cracking.
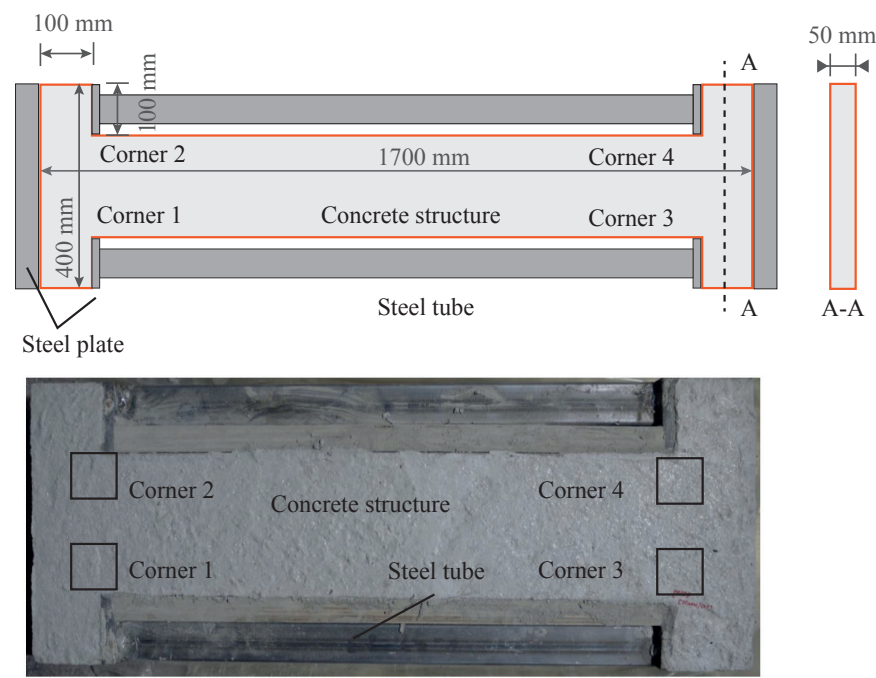

Figure 6: Description of the experimental set-up for the assessment of fracture due to the early-age hydration. A critical working condition is provided, in which cracks can be initiated at four corners.

During the entire testing period, the concrete specimen is stored in a large climate chamber with a constant temperature of $20^{\circ} \mathrm{C}$ and constant relative humidity of $50 \%$. It is noted that the climate chamber is used for this test to avoid the effects of temperature variation on the experimental tools, e.g., steel tube, steel plate. These experimental conditions allow us to limit the complex loads acting on the investigated specimen due to the thermal variation. The concrete layer was fixed on a support structure of wooden form-work which was spanned with a film to avoid any friction between the concrete layer and support structure. The moisture exchange with the ambient medium was also prevented during the tests by means of a plastic foil, which entirely covers the whole specimen. The cracking evolution is investigated over a period of 43 days.

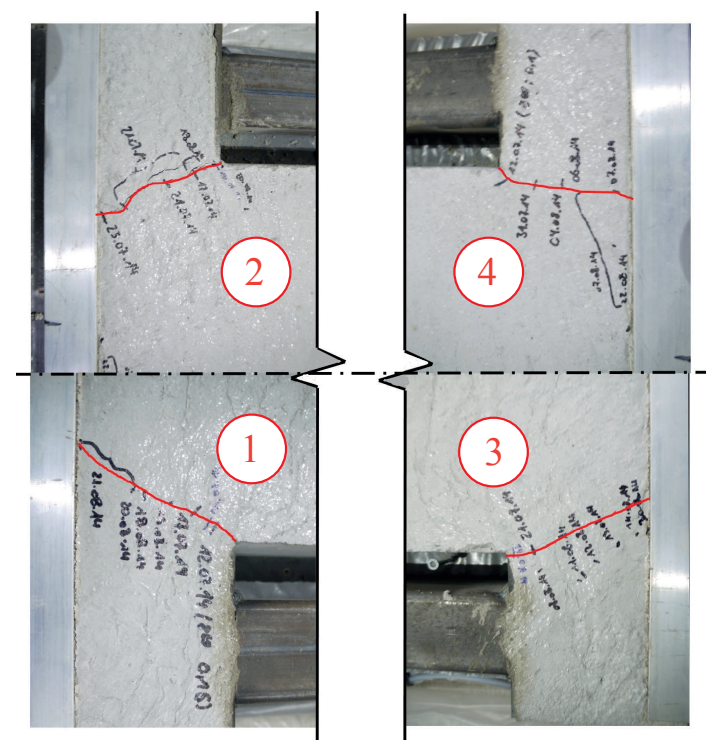

Figure 7: Experimental results of cracking problem observed at time $t=43$ days after casting.

Figure 7 presents the final cracking stage of the specimen at time $t=43$ days, in which the crack paths are marked in red color for the sake of clarity. The cracks completely propagated through the solid domain at all four corners. The quantitative evolution of cracks is provided in Table 3 for each corner of the specimen. Herein, the crack length is defined as the length of the projection of the crack onto the horizontal direction (x-axis).

The fracture problem seems to be quasi-symmetric with respect to the vertical axis. Note that, the small asymmetric can be related to the microstructural effects, imperfections of sample geometry and experimental tools, etc. The earliest time for crack initiation is after one day at the corner C3. The onset of cracks at corner $\mathrm{C} 1 / 2 / 4$ is captured on the third day after casting. The crack propagation mostly takes place at the corners $\mathrm{C} 1$ and $\mathrm{C} 3$ first, while the initiated cracks at corners $\mathrm{C} 2$ and $\mathrm{C} 4$ are stable. They (cracks at $\mathrm{C} 2 / 4$ ) only grow when the corner $\mathrm{C} 1 / 3$ is completely cracked. These phenomena could be explained by the relaxation process of the stresses, which provides the fracture dominant in some regions. Here, the crack growth at $\mathrm{C} 1 / 3$ will relax the stress concentration at $\mathrm{C} 2 / 4$, and stabilize the fracture in these regions. Furthermore, the faster propagation of cracks at $\mathrm{C} 1 / 3$ can be related to the bending problem, which is again due to microstructural effects, distribution of aggregates, and the imperfections of sample geometry.

A delay of the crack propagation is observed, as described in Table 3. The cracks after initiated at the 
first or third day will only continue to grow on the sixth day. This observation can be due to the non-linear evolution of autogenous shrinkage and material strength. First, due to the low material strength, the increase of shrinkage strain will induce cracking. Then, the material strength quickly develops, while the shrinkage still increases linearly. This will stabilize the fracture problem. In the late period, the shrinkage quickly increases, while the development of material strength already slows down. Hence, we continue to capture the crack propagation problem. In the following sections, these effects will be further studied by means of the numerical approach.

Table 3: Measured crack length of corner 1 to corner 4 .

\begin{tabular}{ccccc}
\hline $\begin{array}{c}\text { time } \\
\text { [days }]\end{array}$ & $\begin{array}{c}\text { corner 1 } \\
{[\mathbf{m m}]}\end{array}$ & $\begin{array}{c}\text { corner 2 } \\
{[\mathbf{m m}]}\end{array}$ & $\begin{array}{c}\text { corner 3 } \\
{[\mathbf{m m}]}\end{array}$ & $\begin{array}{c}\text { corner } 4 \\
{[\mathbf{m m}]}\end{array}$ \\
\hline 0.5 & 0 & 0 & 0 & 0 \\
1.0 & 0 & 0 & 10 & 0 \\
3.0 & 10 & 5 & 10 & 5 \\
4.5 & 10 & 5 & 10 & 5 \\
5.0 & 10 & 5 & 10 & 5 \\
6.0 & 20 & 5 & 20 & 5 \\
7.0 & 20 & 5 & 65 & 5 \\
10.0 & 35 & 5 & 100 & 5 \\
12.0 & 100 & 5 & 100 & 5 \\
20.0 & 100 & 25 & 100 & 5 \\
24.0 & 100 & 35 & 100 & 5 \\
30.0 & 100 & 35 & 100 & 30 \\
31.0 & 100 & 35 & 100 & 50 \\
42.0 & 100 & 100 & 100 & 50 \\
43.0 & 100 & 100 & 100 & 100 \\
\hline
\end{tabular}

\section{Model}

In the present work, the early-age behavior of the cement-based materials will be numerically investigated by using the multi-physics computational model based on the chemo-thermo-mechanical coupling in the phase field framework, whose basic concepts are reviewed in the following. For more details and practical implementation aspects, the interested reader can refer to [41, 42, 51.

Let $\Omega \subset \mathbb{R}^{D}$ be an open domain describing a hydration system at time $t$, containing a crack, with $D$ being the space dimension and $\partial \Omega$ its boundary, see Fig. 8 Following the idea of our previous work [41, 42, the state of the system is defined by four state variables, i.e., temperature $T(\mathbf{x})$, displacement $\mathbf{u}(\mathbf{x})$, hydration degree $\alpha(\mathbf{x})$, and phase field $d(\mathbf{x})$. Herein, the variable phase field $d(\mathbf{x})$ is used to describe the damage/fracture level, $d(\mathbf{x})=0$ for intact material and $d(\mathbf{x})=1$ for fully cracked material. Furthermore, the regularized description of cracks is adopted, where the crack geometry is modeled by a continuous quadratic crack surface density function per unit volume $\gamma(d, \nabla d)=\frac{1}{2 \ell} d^{2}+\frac{\ell}{2} \nabla d \cdot \nabla d$ 3 see, e.g., [45, 52, 53. The free energy for the complete chemo-thermo-mechanical system is assumed to

\footnotetext{
3 The crack surface density is based on the introduction of a
}

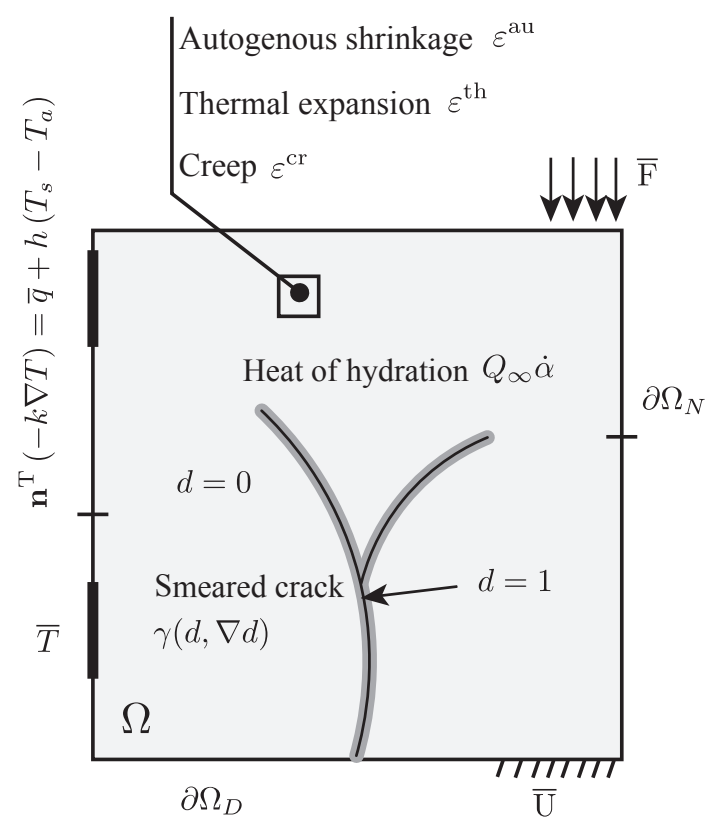

Figure 8: Schematic representation of the investigated system: a solid body containing a crack, in which the hydration reaction takes place during the hardening process.

be a function of the primary variables $\left\{\varepsilon^{e}, \alpha, T, d, \nabla d\right\}$, which can be split into an elastic part of the elastic stored energy $\psi^{e}$, fracture part of fracture surface energy $\psi^{d}$, and a thermo-chemical part $\psi^{T \alpha}(T, \alpha)$. In the regularized framework, it can be expressed as follows

$$
\begin{array}{r}
E(\mathbf{u}, d, \alpha, T)=\int_{\Omega} \psi^{e}\left(\varepsilon^{e}, d\right) \mathrm{d} \Omega \\
+\int_{\Omega} \psi^{d}(d, \nabla d) \mathrm{d} \Omega \\
+\int_{\Omega} \psi^{T \alpha}(T, \alpha) \mathrm{d} \Omega .(1)
\end{array}
$$

The density of the elastic energy $\psi^{e}$ is a function of the phase field $d$ and the elastic strain $\varepsilon^{e}$, which depends on the thermal expansion, autogenous shrinkage and creep strains. The density of fracture energy $\psi^{d}=$ $g_{c}(\alpha) \gamma(d, \nabla d)$, describes the amount of energy released upon the creation of new fracture surface, with $g_{c}(\alpha)$ is the critical fracture resistance influenced by hydration. The density of the thermo-chemical energy $\psi^{T \alpha}(T, \alpha)$ can be expressed as

$$
\psi^{T \alpha}=-\frac{\rho c}{2 T_{0}}\left(T-T_{0}\right)^{2}+\frac{Q_{\infty} \alpha}{T_{0}}\left(T-T_{0}\right)+h(\alpha),(2)
$$

where $\rho c$ is the volumetric heat capacity; $T_{0}$ is the initial temperature; $Q_{\infty} \alpha$ describe the released heat due to hydration reaction, with $Q_{\infty}$ is the total potential heat; $h(\alpha)$ represents the chemical contribution see, e.g., [24, 26] for an explicit formulation.

The free energy is then rewritten as $E=\int_{\Omega} \psi \mathrm{d} \Omega$, in which $\psi$ is the total free density energy defined as follows

$$
\psi=\psi^{e}+\psi^{d}+\psi^{T \alpha}
$$

regularization parameter, often called $\ell$, which controls the size of diffused zone and also affects the critical load of crack 
The chemo-thermal problem of cement hydration is thermodynamically derived by considering the principle of maximum dissipation [41, 42, and described by a BVP that combines the thermodynamic equilibrium governed by the Fourier's law and the Arrhenius law for the evolution of heat release due to the hydration process, as follows

$$
\begin{cases}\rho c \dot{T}=\nabla(\boldsymbol{k} \nabla T)+Q_{\infty} \dot{\alpha} & \text { in } \Omega \\ Q_{\infty} \dot{\alpha}=g(d) A_{T} f(\alpha) \exp \left(-E_{a} / R T\right) & \text { in } \Omega \\ T=\bar{T} & \text { on } \partial \Omega_{D} \\ \mathbf{n}^{\mathrm{T}}(-\boldsymbol{k} \nabla T)=\bar{q}+h_{c r}\left(T_{s}-T_{a}\right) & \text { on } \partial \Omega_{N}\end{cases}
$$

where the degradation function $g(d)=(1-d)^{2}+\zeta$ (with $\zeta \ll 1$, satisfying $g(0) \approx 1, g(1) \approx 0$ and $g^{\prime}(1)=0$, see [45) is introduced to account the fracture effect; $\boldsymbol{k}$ is the local thermal conductivity matrix influenced by fracture process. It is taken following our previous work [41] as $\boldsymbol{k}=g(d) \boldsymbol{k}_{0}$, with $\boldsymbol{k}_{0}$ is the thermal conductivity of the intact material; $R=8.314 \times 10^{-3}\left[\mathrm{~kJ} \mathrm{~K}^{-1} \mathrm{~mol}^{-1}\right]$ is the ideal gas constant; $E_{a}$ is the activation energy; $A_{T}$ is a material parameter, used for the normalized definition of the chemical affinity function $f(\alpha)$, which is here described by the power form for the normalized heat production rate 54

$$
f(\alpha)=\left(\frac{\alpha}{a}\right)^{b}\left(\frac{1-\alpha}{1-a}\right)^{c}
$$

The three constants $a, b$, and $c$ are identified by fitting with the experimental data.

The two last equations in (4), noted here $(4)_{3}$ and (4) 4 describe the mixed boundary condition. Herein $\bar{T}$ and $\bar{q}$ are respectively the prescribed temperature and heat flux at the boundaries $\Omega_{D}$ (Dirichlet part) and $\Omega_{N}$ (Neumann part). The convection condition is represented by the second term in the last equation 44 , with $T_{s}$, $T_{a}$ and $h_{c r}$ are the body surface, air temperature, and convection/radiation coefficient respectively, see, e.g., [41] for more details.

The development of the mechanical properties during the hardening process is modeled by age effects, which are expressed as functions of hydration degree $\bar{\alpha}^{\alpha_{E}}$ for Young's modulus and $\bar{\alpha}^{\alpha_{g_{c}}}$ for fracture resistance, following 29, 55.

$$
\left\{\begin{array}{l}
E(\alpha)=E_{\infty} \bar{\alpha}^{\alpha_{E}} \\
\nu(\alpha)=0.18 \sin \frac{\pi \alpha}{2}+0.5 e^{-10 \alpha} \\
g_{c}(\alpha)=g_{c \infty} \bar{\alpha}^{\alpha_{g_{c}}} \\
\sigma_{c / c t}(\alpha)=\sigma_{c / c t, \infty} \bar{\alpha}^{\alpha_{\sigma_{c}}}
\end{array}\right.
$$

where $E_{\infty}, g_{c \infty}$ are the final Young's modulus, and final fracture energy, respectively.

$$
\begin{aligned}
& \bar{\alpha}^{\alpha_{E}}=\left\langle\frac{\alpha-\alpha_{E}}{\alpha_{\infty}-\alpha_{E}}\right\rangle_{+}^{n_{E}}, \\
& \text { and } \\
& \bar{\alpha}^{\alpha_{g_{c}}}=\left\langle\frac{\alpha-\alpha_{g_{c}}}{\alpha_{\infty}-\alpha_{g_{c}}}\right\rangle_{+}^{n_{g_{c}}}, \\
& \text { and }
\end{aligned}
$$

$$
\bar{\alpha}^{\alpha_{\sigma_{c}}}=\left\langle\frac{\alpha-\alpha_{\sigma_{c}}}{\alpha_{\infty}-\alpha_{\sigma_{c}}}\right\rangle_{+}^{n_{\sigma_{c}}} .
$$

The operator $\langle.\rangle_{+}$denotes the positive operator. $\alpha^{\alpha_{E}}, \alpha^{\alpha_{g_{c}}}$ and $\bar{\alpha}^{\alpha_{\sigma_{c}}}$ are added to define the moment when the material starts having its strength, while $\alpha_{\infty}$ is the final hydration degree. The exponential constants are chosen based on the literature works [34, 56, 57, with $n_{E}=0.5, n_{g_{c}}=0.5, n_{\sigma_{c}}=1.5$.

In the next, the equations for phase field and mechanical problems will be derived based on the principle of maximum dissipation and the principle of minimum energy. We firstly review the construction of the elastic energy in the phase field model. As mentioned in many contributions [45, 51, 58, the unilateral contact formulation is needed to maintain the compressive resistance during the crack closure. The formulation proposed by Miehe et al. 45] with the assumption that damage induced by traction only, is noted being suitable for brittle material like concrete, implying the following expression for the density of elastic energy of the isotropic materials

$$
\psi^{e}=g(d) \psi^{e+}\left(\varepsilon^{e}\right)+\psi^{e-}\left(\varepsilon^{e}\right),
$$

with

$$
\psi^{e \pm}\left(\varepsilon^{e}\right)=\frac{\lambda(\alpha)}{2}\left[\left\langle\operatorname{tr} \varepsilon^{e}\right\rangle_{ \pm}\right]^{2}+\mu(\alpha) \operatorname{tr}\left[\left(\varepsilon^{e \pm}\right)^{2}\right],
$$

where $\varepsilon^{e+}$ and $\varepsilon^{e-}$ are, respectively, the extensive and compressive modes of the elastic strain field $\varepsilon^{e}=\varepsilon^{e+}+$ $\varepsilon^{e-}$.

In the present work, the numerical model will describe the most important multi-physics problems of cement hydration. Hence the elastic strain $\varepsilon^{e}$ is assumed to be affected by thermal expansion strains $\varepsilon^{\text {th }}$, autogenous shrinkage strains $\varepsilon^{\text {au }}$, transient thermal strains $\varepsilon^{\text {ttc }}$, and basic creep strains $\varepsilon^{\text {bc }}$ as

$$
\varepsilon^{e}=\frac{1}{2}\left((\nabla \mathbf{u})^{\mathrm{T}}+(\nabla \mathbf{u})\right)-\varepsilon^{\mathrm{th}}-\varepsilon^{\mathrm{au}}-\varepsilon^{\mathrm{ttc}}-\varepsilon^{\mathrm{bc}} .
$$

The corresponding computational formulation/model for each strain part has been discussed in our previous work [42]. For the sake of brevity, we only summarize the final formulation in Appendix A

The crack phase field evolution law is derived by applying the principle of maximum dissipation to Eq. (1), which can guarantee the irreversibility of the process (see, e.g., [51, 59] for more detail). The equation to be solved for determining $d(\mathbf{x}, t)$ at time $t$ is then obtained

$$
2(1-d) \mathcal{H}-\left(d-\ell^{2} \Delta d\right)-\eta_{d} \dot{d}=0 \text { in } \Omega,
$$


belong with a homogeneous Neumann condition $\nabla d(\mathbf{x})$. $\mathbf{n}=0$ on $\partial \Omega$.

A viscosity coefficient $\eta_{d}$ is added following 45 to describe the rate-dependent properties of fracture behavior at early-age. The local crack driving force $\mathcal{H}(\mathbf{x}, t)$ in Eq. (11) describes a dependence on history [45, and to make loading-unloading possible. Basically, it contains maximum reference energy, or a measure for the maximum tensile strain obtained in the deformation history, with

$$
\mathcal{H}(\mathbf{x}, t)=\max _{\tau \in[0, t]}\left\{\frac{\ell}{g_{c}(\alpha)} \psi^{e+}(\mathbf{x}, \tau)\right\} .
$$

The variational principle for mechanical problem can be defined based on the Euler-Lagrange equations

$$
\mathbf{u}(\mathbf{x})=\operatorname{Arg}\left\{\inf _{\mathbf{u} \in \mathcal{S}_{u}}\left(E(\mathbf{u}, d, \alpha, T)-W^{e x t}\right)\right\}
$$

where $\mathcal{S}_{u}=\left\{\mathbf{u} \mid \mathbf{u}(\mathbf{x})=\overline{\mathbf{u}}\right.$ on $\left.\partial \Omega_{D}, \quad \mathbf{u} \in H^{1}(\Omega)\right\}$ and $W^{e x t}=\int_{\Omega} \mathbf{f} \cdot \mathbf{u} \mathrm{d} \Omega+\int_{\partial \Omega_{N}} \overline{\mathbf{F}} \cdot \mathbf{u} \mathrm{d} \Gamma$ with $\mathbf{f}$ is the body force, $\overline{\mathbf{F}}$ is the prescribed traction over the boundary $\partial \Omega_{N}$, it yields the mechanical problem as follows

$$
\begin{cases}\nabla \cdot \boldsymbol{\sigma}+\mathbf{f}=\mathbf{0} & \text { in } \Omega \\ \mathbf{u}=\overline{\mathbf{u}} & \text { on } \partial \Omega_{D} \\ \boldsymbol{\sigma} \mathbf{n}=\overline{\mathbf{F}} & \text { on } \partial \Omega_{N}\end{cases}
$$

in which, $\overline{\mathbf{u}}$ are the prescribed displacement on the boundary $\partial \Omega_{D}$, and $\boldsymbol{\sigma}$ is the second-order Cauchy stress tensor [41, 42.

In summary, three main coupled problems are defined (i) chemo-thermal problem described by Eq. 4 . (ii) phase field problem via Eq. 11, and (iii) mechanical problem in Eq. 14. All these three problems are solved by a standard FE procedure in a staggered scheme at each time step. More theoretical and practical details can be found in [41, 42, 51].

\section{Identification of model and material parame- ters from experimental tests}

In this section, the material and model parameters, which are required to perform the numerical simulation will be discussed in details. We start by identifying several chemo-thermal parameters using the theoretical approaches proposed in the literature. Then, the other specific parameters will be characterized based on the experimental results of the heat generation tests.

It is worth to mention that the present study aims to provide a performance approach. This approach can accurately predict the chemo-thermo-mechanical/fracture behavior at early-age by using an efficient computational model so that the model inputs can be identified either by simply theoretical formulation or by only a few experimental testing.

\subsection{Chemo-thermal parameters}

Most of the chemo-thermal parameters can be determined based on the concrete mix and the chemical/mineral compositions of the used cement with an acceptable accuracy [15].

The first parameter is the potential heat of the hydration reaction, which can be evaluated following the formulation proposed in the work 60] by

$$
Q_{\infty}=\sum_{i=\text { phases }} \varphi_{i} q_{i}
$$

where $\varphi_{i}$ is the percentage of the corresponding mineral phase $q_{i}$. Using the data listed in Tables 1, 4, we obtain $Q_{\infty}=124013.7\left(\mathrm{~kJ} / \mathrm{m}^{3}\right)$.

Table 4: The potential heat of the hydration reaction for each mineral composition of cement.

\begin{tabular}{llllll}
\hline Phase & $\mathrm{C}_{2} \mathrm{~S}$ & $\mathrm{C}_{3} \mathrm{~S}$ & $\mathrm{C}_{3} \mathrm{~A}$ & $\mathrm{C}_{4} \mathrm{AF}$ & unit \\
\hline Composition & 7.44 & 55.30 & 6.25 & 10.55 & $\mathrm{~kJ} / \mathrm{kg}$ \\
\hline
\end{tabular}

The final hydration degree defined in Eq. (7) depends on the ratio between the water content (denoted w) and cement (denoted c) in the mixture. It is often determined by using the theoretical formulation proposed by Waller [61, as follows

$$
\alpha_{\infty}=1-\exp (-3.3 \times \mathrm{w} / \mathrm{c}) .
$$

With the present mixture given in Table 1 , the final hydration degree is $\alpha_{\infty}=0.885$.

Another parameter, which influences the hydration kinetics, is the activation energy in the chemical reaction law (Arrhenius law) Eq. (4). This parameter can be either experimentally measured or theoretically identified based on the idea introduced in the work of Schindler 62 , reads by

$$
E_{a}=22100 \times P_{\mathrm{C}_{3} \mathrm{~A}}^{0.3} \times P_{\mathrm{C}_{4} \mathrm{AF}}^{0.3} \times S_{\text {Blaine }}^{0.35},
$$

where $P_{\mathrm{C}_{3} \mathrm{~A}}$ and $P_{\mathrm{C}_{4} \mathrm{AF}}^{0.3}$ are respectively the proportion of $\mathrm{C}_{3} \mathrm{~A}$ and $\mathrm{C}_{4} \mathrm{AF}$ phases; $S_{\text {Blaine }}$ is the specific surface area of cement, it reaches $S_{\text {Blaine }} \approx 0.31 \mathrm{~m}^{2} / \mathrm{g} 63$. Using the data of Table 2 the activation energy for the cement CEM II/A LL $42.5 \mathrm{~N}$ is $E_{a}=51.53 \mathrm{~kJ} / \mathrm{mol}$. This value is comparable with one of the similar cement obtained from experiment in 64.

Beside the potential heat of the hydration reaction, the thermal transfer problem described by Fourier's law (4) 1 also requires two parameters, which are the thermal conductivity and the thermal capacity. Following the idea in the work of Mounaga 65, these two parameters can be evaluated based on the composition of the concrete mix by the following expression

$$
k=\sum_{i=\text { phases }} \varphi_{i} k_{i}, \text { and } \rho c=\sum_{i=\text { phases }} \varphi_{i} \rho c_{i} .
$$

Using the literature data listed in Table 5 , we obtain $k=2.636 \mathrm{~W} /(\mathrm{m} . \mathrm{K})$, and $\rho c=2536.51 \mathrm{~kJ} /\left(\mathrm{K} . \mathrm{m}^{3}\right)$ 
Table 5: Thermal conductivity for each composition of concrete mix.

\begin{tabular}{llll}
\hline Composition & Aggregates & Cement & Water \\
\hline Thermal conductivity $\left[\mathrm{W} \cdot \mathrm{m}^{-1} \cdot \mathrm{K}^{-1}\right]$ & 3.089 & 1.230 & 0.599 \\
Thermal capacity $\left[\mathrm{J} \cdot \mathrm{kg}^{-1} \cdot \mathrm{K}^{-1}\right]$ & 820 & 760 & 4186 \\
\hline
\end{tabular}

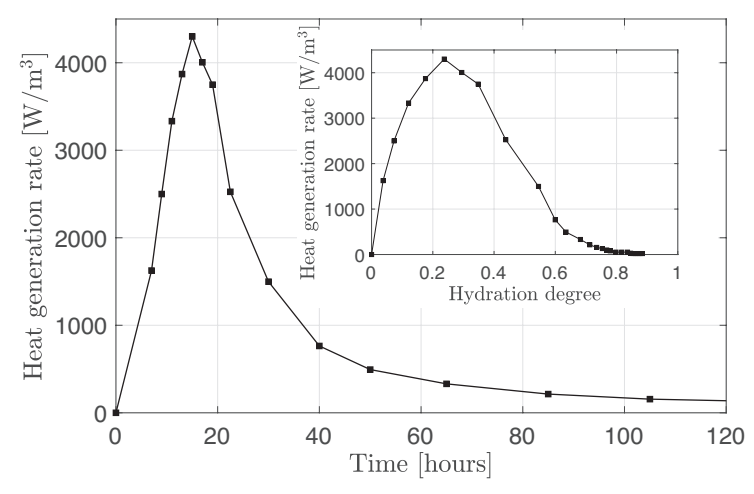

Figure 9: Heat generation rate of the investigated concrete, with respect to time and with respect to hydration degree.

The two last parameters needed for the chemo-thermal model are the chemical affinity function $f(\alpha)$ and $A_{T}$, which are often identified from the experimental results of the isothermal calorimetry. The curve of accumulated heat depicted in Fig. 4 is considered. The heat generation rate is derived by taking the numerical derivation. The obtained result is plotted with respect to hardening time in Fig. 9. Furthermore, based on the definition of hydration degree (amount of released heat to total heat generation) we can construct the evolution of hydration degree in time. By coupling these two results: the evolution of hydration degree in time and the development of heat generation rate in time, we are able to get the evolution of heat generation rate with respect to the hydration degree, as depicted in small plot in Fig. 9. The chemical affinity function is then obtained by normalizing this curve to the maximal heat generation rate, see Fig. 10 The fitting procedure is applied to identify $a, b, c$ in Eq. 5 Finally we obtain $a=0.213 ; b=0.95 ; c=3.51$. The approximated curve is also depicted in Fig. 10 , demonstrating a high correlation with the experimental result.

The parameter $A_{T}$ can be determined via the relation

$$
\dot{Q}=A_{T} f(\alpha) \exp \left(-E_{a} / R T\right) .
$$

By evaluating at the point where the hydration process gets the maximal heat generation rate, it gives $A_{T} \approx 3.6$ $\mathrm{GW} / \mathrm{kg}$.

\subsection{Mechanical parameters}

The Young's Modulus and tensile/compressive strength of the concrete $\mathrm{C} 20 / 25$ has been experimentally determined in the section 2.2

The age effects parameters, $\alpha_{E}$ and $\alpha_{g_{c}}$ defining the moment when the material starts developing strength are experimentally identified based on the evolution of

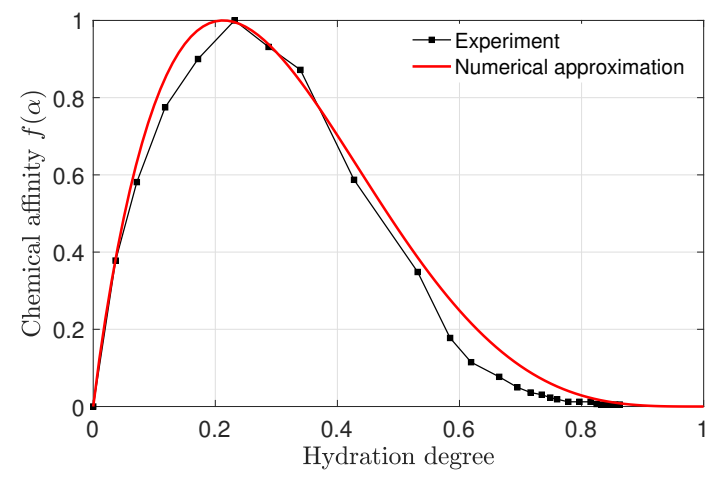

Figure 10: Identification of the chemical affinity function: normalized heat generation rate and corresponding numerical approximation curve.

the material properties with respect to the hydration degree. The concrete C20/25 in this work has exhibited its strength in concurrent with the initiation of hydration degree (see Fig. 2). Hence, for the sake of simplicity, we choose $\alpha_{E}=\alpha_{g_{c}}=0.01$, which is identical to the initial hydration degree.

Another parameter plays an essential role in stress estimation at early ages is the thermal expansion coefficient, which exhibits significant changes during the hardening process at early ages [35, 66, 67]. However, quantification of this parameter has remained extremely challenging due to the difficulty in establishing a clear separation between the thermal deformation and the autogenous shrinkage deformation 67. Hence, it is often assumed to be a constant, which is equal to the reference value for hardened concrete. Several attempts have been made in the literature to establish a theoretical formulation for the evaluation of $\beta$, such as the study of Neville 68, in which $\beta$, is chosen depending on the aggregate type. We choose here a constant $\beta \approx 10\left(\mu \mathrm{m} \cdot \mathrm{m}^{-1} \cdot \mathrm{K}^{-1}\right)$ for the present concrete mix. The material constant $\kappa$ used to model the autogenous shrinkage strain in Eq. A.1 is identical with the autogenous shrinkage strain at the end of hydration process when $\alpha=\alpha_{\infty}$, regarding the result in Fig. 5 , and by using an extrapolated tangential value, we obtain $\kappa \approx 200\left(\mu \mathrm{m} . \mathrm{m}^{-1}\right)$.

\subsection{Summary of obtained parameters}

The summary of all model/material parameters are given in Table 6 .

For the parameters of the creep model, the retardation times $\tau_{b c, \infty}^{i}$ can be chosen as constants and according to the suggestion in [25, 43], which reaches $\tau_{b c, \infty}^{1}=0.1$ days, $\tau_{b c, \infty}^{2}=1$ days, and $\tau_{b c, \infty}^{3}=10$ days. The coefficient of the transient thermal creep, activation energy, and spring stiffness of basic creep models have been chosen following 
Table 6: Material properties of the concrete C20/25.

\begin{tabular}{llllll}
\hline Prt & Value & Unit & Prt & Value & Unit \\
\hline$\rho c$ & 2536.51 & $\mathrm{~kJ} /\left(\mathrm{K} \cdot \mathrm{m}^{3}\right)$ & $\alpha_{a u}$ & 0.01 & - \\
$k$ & 2.636 & $\mathrm{~W} /(\mathrm{m} . \mathrm{K})$ & $\alpha_{E}$ & 0.01 & - \\
$Q_{\infty}$ & 124014 & $\mathrm{~kJ} / \mathrm{m}^{3}$ & $\alpha_{g_{c}}$ & 0.01 & - \\
$h$ & 8 & $\mathrm{~W} /\left(\mathrm{m}^{2} . \mathrm{K}\right)$ & $\alpha_{\infty}$ & 0.885 & - \\
$\beta$ & 10 & $\mu \mathrm{m} /(\mathrm{m} . \mathrm{K})$ & $E_{a}$ & 51.53 & $\mathrm{~kJ} / \mathrm{mol}$ \\
$\kappa$ & 200 & $\mu \mathrm{m} / \mathrm{m}$ & $\nu$ & 0.2 & - \\
$E_{\infty}$ & 30 & $\mathrm{GPa}$ & $A_{T}$ & 3.6 & $\mathrm{GW} / \mathrm{kg}$ \\
$g_{c, \infty}$ & 164.5 & $\mathrm{~N} / \mathrm{m}$ & $\sigma_{c, \infty}$ & 22.5 & $\mathrm{MPa}$ \\
\hline
\end{tabular}

to the one proposed in [15, 43, and listed in Table 7. It is noted that our concrete is not exactly the same as the one used in 43, i.e., the parameters of creep models could be different. Characterization of these parameters using the experiment is recommended. However, this task is extremely challenging due to the difficulty in the separation of creeps from shrinkage strain (autogenous, drying), and thermal strain. In this study, the effects of basic and transient thermal creeps are considered to explain the delay of fracture qualitatively. Hence, we simply use the parameters from the literature.

Table 7: Material properties for creep model (Ref. [15, 43).

\begin{tabular}{llllll}
\hline Pmt & Value & Unit & Pmt & Value & Unit \\
\hline$\lambda_{\text {ttc }}$ & $1.38 \mathrm{E}-12$ & $(\mathrm{~K} . \mathrm{Pa})^{-1}$ & $E_{a c}$ & 17.4 & $\mathrm{~kJ} / \mathrm{mol}$ \\
$k_{b c, \infty}^{1}$ & 1300 & $\mathrm{GPa}$ & $\tau_{b c}^{1}$ & 0.1 & Days \\
$k_{b c, \infty}^{2}$ & 650 & $\mathrm{GPa}$ & $\tau_{b c}^{2}$ & 1 & Days \\
$k_{b c, \infty}^{3}$ & 130 & $\mathrm{GPa}$ & $\tau_{b c}^{3}$ & 10 & Days \\
\hline
\end{tabular}

\section{Comparison between experimental observa- tion and numerical prediction}

In this section, we will carry out numerical simulations to reproduce the experimental observations reported in section 2. The numerical inputs are based on the identified material/model parameters (see section 4). The FEM models and corresponding boundary conditions will be constructed to mimic the experimental setup presented in section 2. Both shrinkage and fracture behaviors will be investigated in details. The numerical predictions are not only expected to compare with the experiment, but also aiming to gain insight into the complex chemo-thermo-mechanical/fracture behavior of the cement-based materials.

\subsection{Comparison of shrinkage behavior}

The experimental results provided in section 2.3 have demonstrated the critical shrinkage behavior of nonreinforced concrete $\mathrm{C} 20 / 25$. The shrinkage strain is high, about $350 \mu \mathrm{m} / \mathrm{m}$ at the end of the hydration process. This property will be numerically reproduced by using the computational approach based on the coupled chemo-thermo-mechanical model. Especially, the effects of transient thermal creep and basic creep strain at early-age will also be considered.
Both two-dimensional (plane stress) and threedimensional models are adapted to this aim, in which the FEM mesh is constructed with the same dimensions as the real specimen. The detailed description of the sample and its working condition are depicted in Fig. 11(a). Thanks to the presence of the neoprene layer, the influences of the form-work on the mechanical boundary conditions (restriction of displacement at the sample boundaries) are negligible. Moreover, the neoprene layer's thickness is very small and this layer was detached from concrete during the hardening process. Hence, its effects on the thermal transfer problem are also negligible. The numerical simulation will be performed over a time period $t=0-84$ days, which is equal the experimentally recorded results. The recorded data of the ambient temperature is used as an input for the numerical simulation to capture the effects of temperature variation on the hydration process. The time step is chosen $\Delta t=3$ hours. A linear interpolation is adopted for the case that the considered time step is not conforming with the experimental data. Both situations with and without consideration of creep effects will be analyzed. In addition, the fracture is not observed in the experiment. Therefore, for the sake of simplicity, the fracture problem is not considered here.

A comparison between the experimental observation and numerical predictions is plotted in Figs. 11(b)(c). For the sake of clarity, the shrinkage strain is plotted for the same moment as in the experiment, with the time step $\Delta t=1$ day for the first 30 days, and then $\Delta t=2$ days or 3 days for the rest. All three models (2D/3D without consideration of creep effects, and $2 \mathrm{D}$ with consideration of creep) quantitatively reproduce the experimental findings for the first period of blocking drying shrinkage. More specifically, for the period $t=[0-10]$ days, the proposed approach accurately predicts the non-linear evolution of shrinkage strain, such as the slow evolution in the first few days and the quick evolution in the following days. The results of both the 2D models with and without consideration of creep are quasi-identical for first 2-3 days (the creep effects are negligible at very early age period), and its total shrinkage strain is a bit rather than that one of the $3 \mathrm{D}$ model. An explanation for this small difference is due to the insulated assumption on the upper and lower surfaces in $2 \mathrm{D}$ model, which induces the overestimation of concrete temperature and thus accelerating the hydration process with respect to the full $3 \mathrm{D}$ model. However, in the later period, when the rate of heat generation is reduced, the predictions of the $2 \mathrm{D}$ model is now similar to the $3 \mathrm{D}$ one. The studied sample is thin (thickness of $60 \mathrm{~mm}$ ). Hence, the temperature of inside concrete will equalize the ambient temperature if there is no heat generation. The obtained results confirm that the $2 \mathrm{D}$ model in such a situation can give predictions with acceptable accuracy.

The process of autogenous shrinkage seems to be completed after three weeks. As demonstrated in Fig. 11(b), we obtain a stable shrinkage strain within the period $t=[22-28]$ days. In the next period $t>28$ days, 
when the drying process is activated (the plastic foil is removed), the total shrinkage strain continues increasing. The shrinkage strain is now mainly due to the drying shrinkage and the creep. The prediction of the $2 \mathrm{D}$ model with consideration of creep shows a significant contribution of creep strain, which provides the non-linear evolution of total shrinkage strain within the period $t>21$ days. The difference between numerical prediction and experimental observation in the final period is here due to the contribution of the drying shrinkage, which is unfortunately neglected in the present model. It is worth to mention that this study is dedicated to investigating the influences of autogenous shrinkage. A new coupled multi-physics model, taking into account the effects of moisture transfer will be further investigated in the future works.

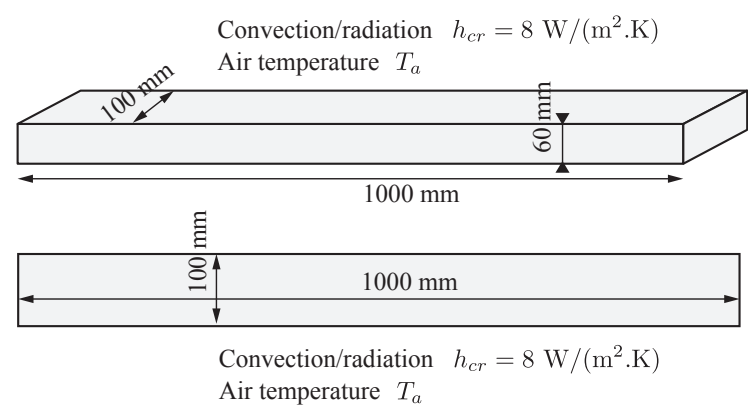

(a) Description of sample geometry and boundary conditions

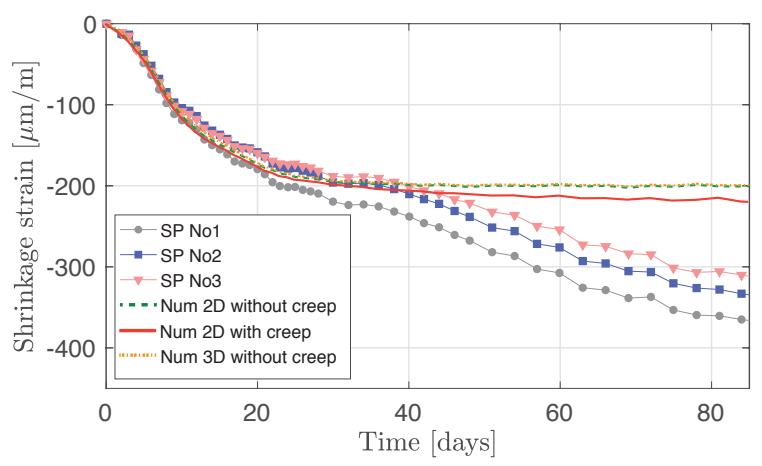

(b) Comparison between experimental observations and numerical predictions using chemo-thermo-mechanical model

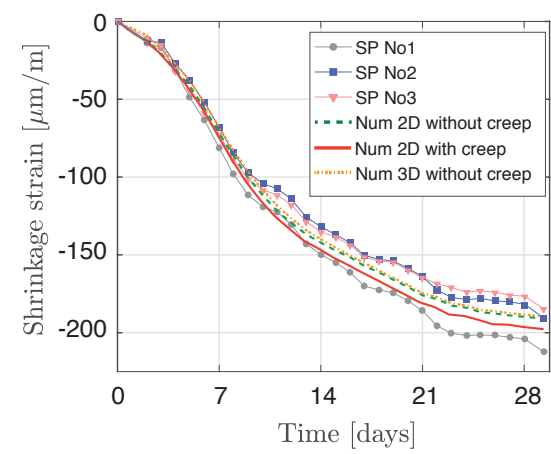

(c) Comparison between experimental observations and numerical predictions for the first time period [0 - 28] days

Figure 11: Critical shrinkage properties of the unreinforced concrete $\mathrm{C} 20 / 25$. The numerical model based on the chemo-thermomechanical coupling is able to accurately predict the evolution of shrinkage strain.

\subsection{Comparison of fracture behavior}

The high sensibility to shrinkage of the non-reinforced concrete $\mathrm{C} 20 / 25$ is risky for the durability of structures made of this material, e.g., the loss of material performance due to the initiation and propagation of cracking when subject to a critical working condition as mentioned in section 2.4. The numerical simulation based on the computational model described in section 3 will be performed to reproduce the experimental findings. The objective is not only to validate the proposed model but also to better understand the cause of cracking and several special fracture behaviors such as very-early-age crack initiation (at time 0.5-1 days after casting), delay of crack propagation, and unsymmetrical crack growth.

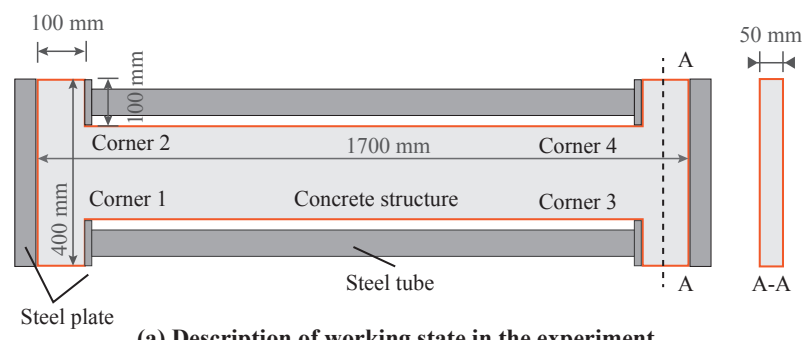

(a) Description of working state in the experiment

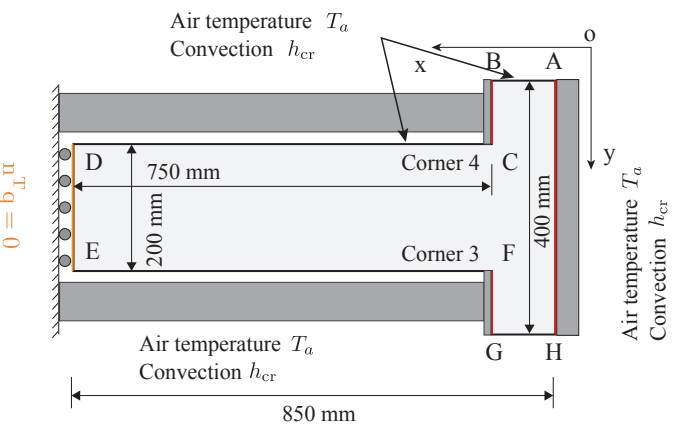

(b) Proposed numerical scheme with different convection conditions

Figure 12: Geometry and boundary conditions of the numerical model.

In the numerical model, for the sake of simplicity, only half of the investigated system is modeled (thank to the symmetry of the sample geometry), and the quasisymmetrical fracture problem obtained in the experiment. As demonstrated in the previous section, the sample geometry is small and thin. Therefore, the twodimensional model is able to accurately predict the early age behavior of the investigated problem, see Fig. 12 The steel tube and steel plate are made of AISI 4130 Alloy Steel, and its thermo-mechanical properties following [69] are provided in Table 8. Note that, to improve the efficiency of the numerical simulation, several simplifications and assumptions will be used to construct the boundary conditions. Firstly, for the heat transfer problem, the investigated structure is convective with the environment via two ways: (i) direct with air environment in the edge $\mathrm{AB}, \mathrm{CD}, \mathrm{EF}$, and $\mathrm{HG}$. This phenomenon will be modeled by the convection coefficient $h_{\mathrm{cr}}=8$ $\mathrm{W} /\left(\mathrm{m}^{2} . \mathrm{K}\right)$, and the air temperature $T_{a}=20^{\circ} \mathrm{C}$, equal the chamber temperature; (ii) in contact with steel plate, 
and the steel plate is convective to air environment. The interface between steel-concrete is modeled here with the thermal conductance condition with high conductance coefficients $h_{c d}=10^{4} \mathrm{~W} /\left(\mathrm{m}^{2} . \mathrm{K}\right)$. Then, the convection/radiation condition is applied to model steel/air heat transfer [40. Secondly, for the mechanical boundary conditions, the $x$-displacements at the symmetrical edge of both steel tube and concrete specimen DE are fixed. The three concrete edges CB, FG and AH have been glued with steel since casting. A fiction-contact model for the interfacial region between steel/concrete can be a good solution to model these effects. However, the numerical implementation of this model still remains challenging, and it is not straightforward to identify these material/model parameters. In addition, due to the shrinkage strain acts on the steel plate/tube, which makes the cohesion between concrete/steel to be much stronger. Hence, for the sake of simplicity and efficiency, a perfect cohesion interface model (infinite coefficient of friction) is adopted, i.e., the $x, y$-displacements at boundary regions of the sample will be identical to the $x, y$-displacements at boundary regions of steel plate.

Table 8: Material properties of the AISI 4130 Alloy Steel.

\begin{tabular}{llllll}
\hline Prt & Value & Unit & Prt & Value & Unit \\
\hline$\rho c_{\mathrm{s}}$ & 3744 & $\mathrm{~kJ} /\left(\mathrm{K} \cdot \mathrm{m}^{3}\right)$ & $E_{\mathrm{s}}$ & 200 & $\mathrm{GPa}$ \\
$k_{\mathrm{s}}$ & 42.7 & $\mathrm{~W} /(\mathrm{m} . \mathrm{K})$ & $\nu_{\mathrm{s}}$ & 0.3 & - \\
$\beta_{\mathrm{s}}$ & 7 & $\mu \mathrm{m} /(\mathrm{m} . \mathrm{K})$ & $h_{\mathrm{cr}}$ & 8 & $\mathrm{~W} /\left(\mathrm{m}^{2} . \mathrm{K}\right)$ \\
\hline
\end{tabular}

Concerning the internal length $\ell$ of the phase field model, as discussed in [58, 70, 71, by using an analysis of the compression of a one-dimensional bar, a rough relationship among $\ell$ and material parameters $\left(E, g_{c}\right)$ and the compressive strength $\sigma_{c}$ was constructed, which reaches

$$
\ell=\frac{81 E g_{c}}{512(1+\nu) \sigma_{c}^{2}} .
$$

It is worth to mention that the internal length $\ell=$ $f\left(E, \nu, g_{c}, \sigma_{c}\right)$ directly affects the crack initiation problem. Therefore, in this study, the value of $\ell$ is regularly updated along with the development of $E, g_{c}$ and $\sigma_{c}$. With the data provided in Table 6, it implies $\ell \approx 2 \mathrm{~mm}$ at the end of the hydration process. The structure is meshed using triangular elements with $h_{e}^{\max }=8 \mathrm{~mm}$ and $h_{e}^{\text {min }}=0.75 \mathrm{~mm}$ for the critical region, satisfying the condition $\ell \geq 2 h_{e}$ for having several elements inside the diffused region. The initial conditions $T_{0}=20^{\circ} \mathrm{C}$ and $\alpha_{0}=0.01$ are chosen for whole system. The incremental time step is taken as $\Delta t=300 \mathrm{~s}$ for the total of 3000 time steps.

The crack morphologies, along with the local distribution of temperature, and hydration degree are plotted in Fig. 13 at the age of $t=24$ hours. As discussed in the previous sections, the increase of concrete temperature is not significant (concrete temperature is close to the ambient temperature). We believe that the occurrence of a crack is mainly related to the acceleration period of the hydration process. In this period, the autogenous shrinkage quickly increases while the material strength is still very low. Hence, the crack initiation and propagation phenomena are captured. The numerical result shows a crack at corner 3 with crack length about $10.21 \mathrm{~mm}$, compared to the crack length of $10 \mathrm{~mm}$ in the experiment, demonstrated a very good agreement. In addition, we also observe the nucleation of damage at corner 4 , which is not captured by the experiment due to the limitation of experimental tools (resolution of the observation, difficulty of damage characterization). The present model accurately predicts the delay of crack propagation due to the non-linear evolution of shrinkage and material strength. Note that, both numerical models, with and without consideration of creep (AC and $\mathrm{NC}$ ) seem to give the same results in this period. It means the effects of creeps are considered to be negligible for the very-early-age stage of cement hydration.

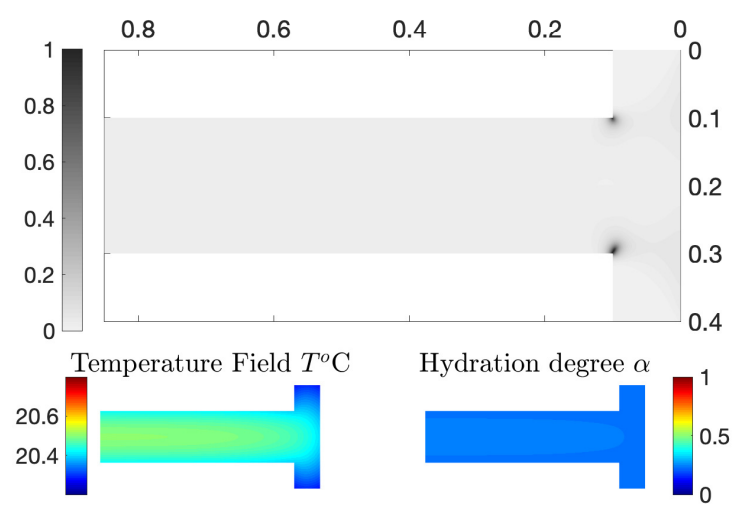

Figure 13: Crack morphology at time $t=24$ hours.

At time $t=72$ hours (or the concrete age of $t=$ 3 days), again, there is no significant difference between the two models (NC) and (AC), see Fig. 14. It confirms one more time the negligible effects of creep strains at very-early-age, i.e., a few days after casting. Thus, the fracture behaviors of both models are quasi-identical. More specifically, the obtained crack length at corner 3 is $10.34 \mathrm{~mm}$ for (NC) model and $10.26 \mathrm{~mm}$ for (AC) model. The crack propagation is captured at corner 4 as well, for instance, the crack length is $5.26 \mathrm{~mm}$ for (NC) and $5.13 \mathrm{~mm}$ for (AC). The stress relaxation due to the creep effects, which slows down the crack propagation phenomena. Hence, the crack length obtained by $(\mathrm{AC})$ model is always smaller than the one obtained by (NC) model. It is worth to note that both models quantitatively reproduce the experimental observation, where the experimentally measured crack lengths are $10 \mathrm{~mm}$ at Corner 3 and $5 \mathrm{~mm}$ at Corner 4 . The unsymmetrical fracture is also captured by the numerical simulation. An explanation for that phenomenon can be related to the interaction between two cracks. Basically, crack propagation will induce stress relaxation for the whole structure. Hence, in the case of cracking at one zone (ZA) prevails on another zone (ZB), that will 


\begin{tabular}{ccccccc}
\hline $\begin{array}{c}\text { time } \\
{[\text { days }]}\end{array}$ & $\begin{array}{c}\text { C3-EXP } \\
{[\mathbf{m m}]}\end{array}$ & $\begin{array}{c}\text { C3-NC } \\
{[\mathbf{m m}]}\end{array}$ & $\begin{array}{c}\text { C3-AC } \\
{[\mathbf{m m}]}\end{array}$ & $\begin{array}{c}\text { C4-EXP } \\
{[\mathbf{m m}]}\end{array}$ & $\begin{array}{c}\text { C4-NC } \\
{[\mathbf{m m}]}\end{array}$ & $\begin{array}{c}\text { C4-AC } \\
{[\mathbf{m m}]}\end{array}$ \\
\hline 0.5 & 0 & 0 & 0 & 0 & 0 & 0 \\
1.0 & 10 & 10.21 & 10.21 & 0 & 0 & 0 \\
3.0 & 10 & 10.34 & 10.26 & 5 & 5.26 & 5.13 \\
4.5 & 10 & 37.61 & 10.33 & 5 & 5.27 & 5.13 \\
5.0 & 10 & 62.51 & 10.36 & 5 & 5.27 & 5.13 \\
6.0 & 20 & 96.43 & 21.11 & 5 & 5.38 & 5.13 \\
7.0 & 65 & 100.00 & 67.11 & 5 & 5.59 & 5.13 \\
10.0 & 100 & 100.00 & 100.00 & 5 & 7.12 & 5.14 \\
\hline
\end{tabular}

Table 9: Quantitative comparison of crack evolution between experiment and numerical prediction at corner 3 and corner 4 for both models (NC) and (AC). The obtained results demonstrated the important effects of creep on the early-age fracture behavior of cement-based materials.

relax the stress concentration and stabilize the cracking at region ZB. In our experiment, within the period $t=[3-10]$ days, we observe that the crack mostly propagates at corner 3 , whereas the fracture phenomena at corner 4 are quasi-stable.

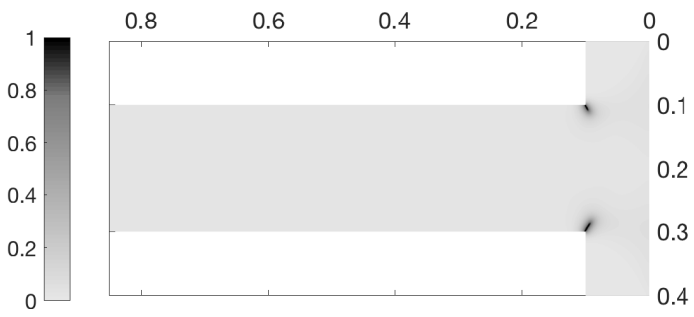

(a) model without considering creep (NC)

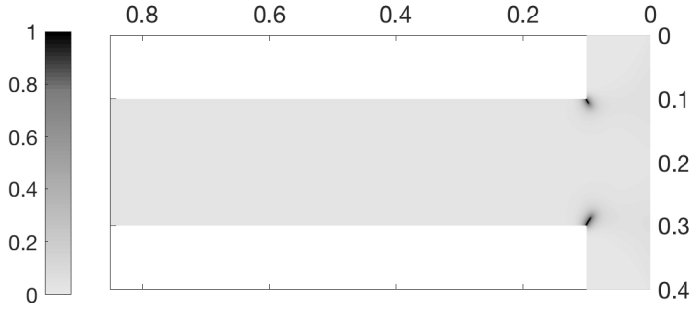

(b) model with considering creep (AC)

Figure 14: Crack morphology at time $t=72$ hours.

Starting from the moment $t=80$ hours after casting, the influences of creep strains become more significant. The difference of numerical results between the model (NC) and (AC) are clearly captured in Table 9. After crack initiation ( $t=1$ day), the model (NC) predicts that the crack growth will slow down a bit, then continue quickly propagate within the time period $t=4-6$ day, and the crack at corner 3 will completely propagate through the structure after $t=6$ days, as described in Fig. 15(a).

In the (AC) model, when the effects of creep strains are taken into account, the delay in crack propagation is numerically obtained. At time $t=6$ days, instead of fully cracked as the prediction of the model (NC), the $(\mathrm{AC})$ one predicts that the crack length at corner 3 is about of $21.11 \mathrm{~mm}$, see Fig. 15(b). This value is in good agreement with the experimental results with

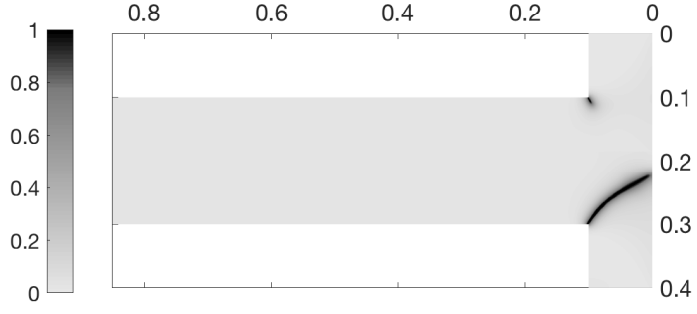

(a) model without consideration of creep (NC)

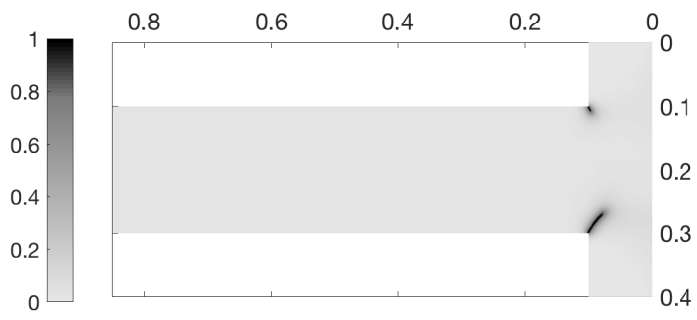

(b) model with consideration of creep (AC)

Figure 15: Crack morphology at time $t=144$ hours.

the measured length of $20 \mathrm{~mm}$. A high correlation between simulation and experiment is also obtained for the fracture phenomena at time $t=7$ days and $t=10$ days, as depicted in Table 9. The concrete structure is fully cracked at corner 3 after casting 10 days, see Fig. 16 .

Figure 17 presents a quantitative comparison of crack morphology obtained from the experiment and the one predicted by the numerical model (AC). Both results in corner 3 and 1 (via symmetrical operator) are represented. More specifically, the angle makes by the position of crack initiation (at the corner) and the end crack tip (at specimen boundary), with respect to horizontal direction, will be used as the comparison indicator. We noted an acceptable agreement for corner 3 , the crack angle obtained by experiment is $156.63^{\circ}$, whereas one of the simulations is $142.6^{\circ}$. A much better correlation is obtained for corner 1 , with $145.8^{\circ}$ for the experiment and $142.6^{\circ}$ for the simulation. Note that the crack morphology, trajectory and propagation tendency are often affected by concrete microstructures at a smaller scale [51, 72, such as geometry, properties, distribution of ag- 


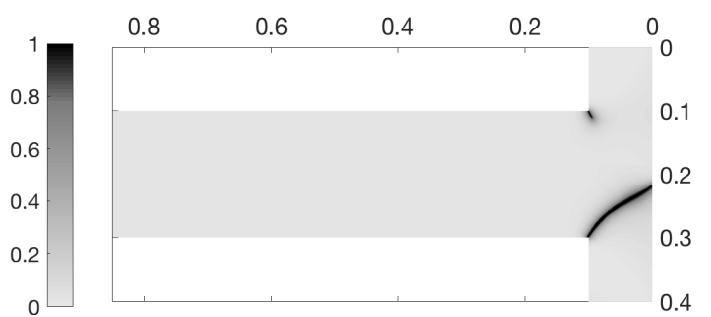

(a) model without consideration of creep (NC)

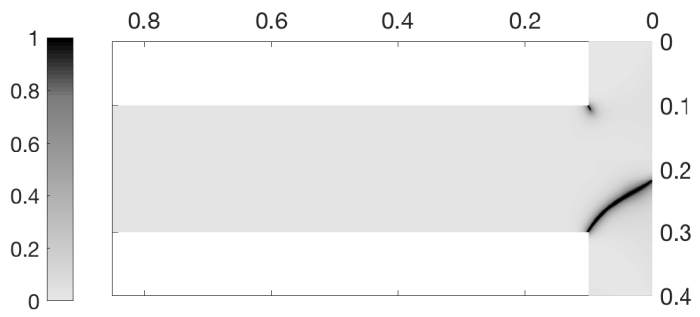

(b) model with consideration of creep (AC)

Figure 16: Crack morphology at time $t=240$ hours.

gregates and porosity, etc. In the present work, even by using only a simple 2D-model with the assumption that material is homogeneous the numerical model is always able to capture the most important fracture phenomena observed in the experiment.

In summary, the unreinforced concrete C20/25 exhibits a high risk of early-age cracking. Two most critical periods are noted: (i) the first one at very-early-age, about 1-2 days after casting, corresponding to the acceleration period, is mainly due to the development of autogenous shrinkage, while the material strength is still very low; (ii) the second critical period takes place at the age of about 6 days. Within this period, the material strength slowly develops, while the shrinkage still increases quickly. Hence, the initiated cracks continue to propagate, which finally leads to the complete collapse of the structure. The numerical simulation clarified the role of creep strains on fracture behavior. No significant effects are captured at period $t<3$ days. However, the transient thermal creep and basic creep become more important after 5 days. Their main role are mostly related to the retardation of the crack growth.

\section{Conclusions}

In this work, we have presented an approach combining numerical simulation and experimental techniques to investigate the early-age properties (thermal-mechanical and fracture behaviors) of the non-reinforced concrete. More specifically, in the first part, the behavior of thermo-mechanics, shrinkage property and risk of cracking are experimentally studied by using the standardized material tests. The mechanical and several thermal parameters are also characterized by using experimental methodologies. The identification of all model inputs is then clarified. We show that most of the chemo-thermal parameters can be theoretically quantified based on the concrete mix and the chemical/mineral compositions of the cement. Only several standard tests are needed to determine the inputs of the numerical model. The experimental observations of shrinkage and fracture are compared to the numerical predictions. A good agreement is archived.

The obtained results show the critical shrinkage properties of non-reinforced concrete of normal strength class C20/25 with high w/c ratio. A high risk of cracking is also captured. The major damage cause is noted due to the autogenous shrinkage. The important effects of creeps at the early-age, for instance, transient thermal creep and basic creep are also captured at the age about 5-7 days after casting.

Another important finding of this work is the prediction capacity of the coupled chemo-thermo-mechanical model in the phase field framework. By only using a simple simulation with the assumption of homogeneous material, and along with a few testing for model inputs, the computational model has been able to accurately reproduce the complex early-age behavior of cementbased materials observed in the experiment. It is very promising to apply this numerical framework to study the real applied civil engineering problem.

\section{Acknowledgments}

The support of this work enjoys from SeRaMCo project (Secondary Raw Materials for Concrete Precast Products), through the transnational cooperation projects in North-West Europe (Interreg NWE), NWE320 is gratefully acknowledged.

\section{Appendix A. Model strain components}

The thermal strain due to the temperature evolution and the autogenous shrinkage strain related to the evolution of hydration are described as follows

$$
\begin{aligned}
& \varepsilon^{\text {th }}=\beta\left(T-T_{0}\right) \mathbf{1} \\
& \text { and } \quad \varepsilon^{\mathrm{au}}=-\kappa\left\langle\frac{\alpha-\alpha_{a u}}{\alpha_{\infty}-\alpha_{a u}}\right\rangle_{+} \mathbf{1},
\end{aligned}
$$

where $\beta$ is the thermal expansion coefficient, and $\kappa$ is a material constant. The evolution of autogenous shrinkage is starting when hydration degree is greater than the mechanical percolation threshold, i.e., $\alpha(\mathbf{x})>$ $\alpha_{a u}$.

The transient thermal creep strain is considered following the work [73], reads

$$
\dot{\varepsilon}^{\mathrm{ttc}}=\lambda_{\mathrm{ttc}}|\dot{T}| \sigma
$$

where $\lambda_{\text {ttc }}$ is a material parameter characterizing the stress-induced thermal strain due to the transient temperature history, and its appropriate choice can be found in [3, 74, for instance, as $\lambda_{\mathrm{ttc}}=1.38 \times 10^{-12} \mathrm{~Pa}^{-1} \mathrm{~K}^{-1}$. The second-order Cauchy stress tensor $\boldsymbol{\sigma}$ is defined as

$$
\boldsymbol{\sigma}=\partial_{\boldsymbol{\varepsilon}^{e}} \psi^{e}
$$




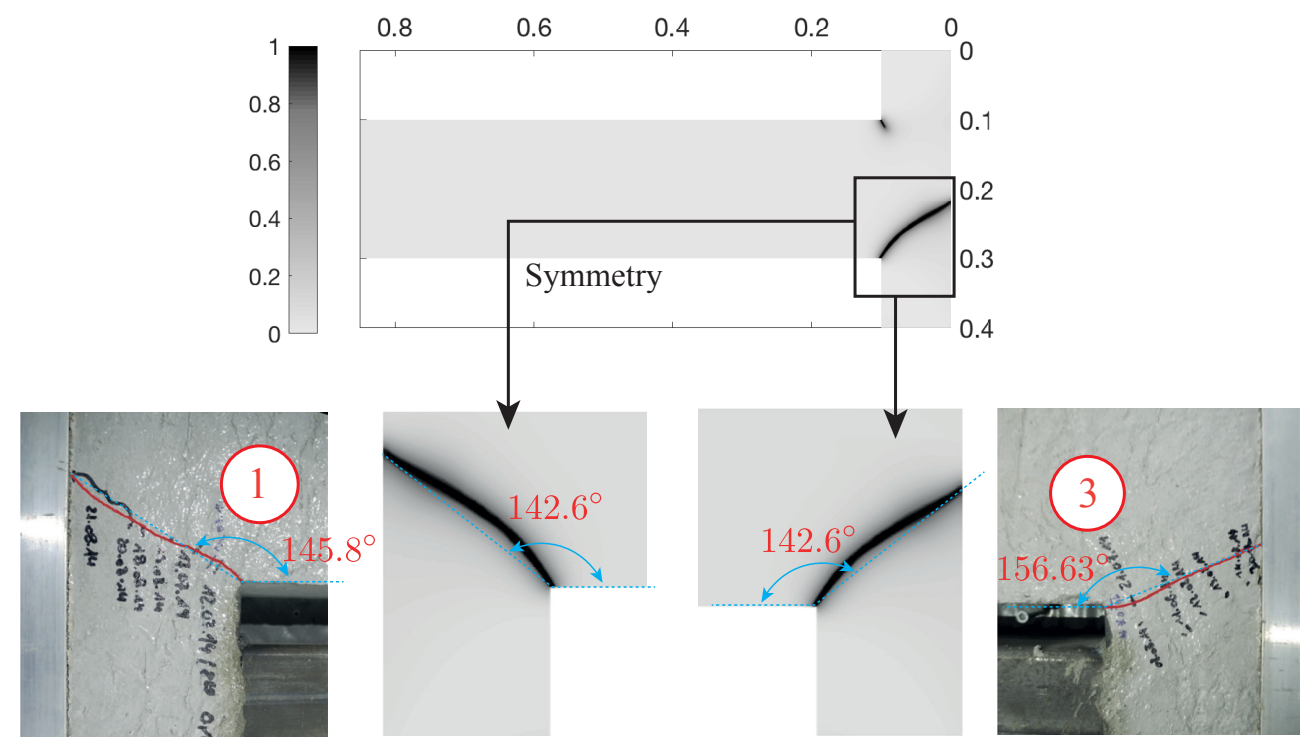

Figure 17: Quantitative comparison of crack morphology between experiment and simulation.

In this study, the basic creep is modeled by rheological elements (spring and dashpots) using Kelvin-Voigt chain with three units combined in serial. For each KelvinVoigt unit, the evolution of basic creep strain is described by the following relation

$$
\tau_{b c}^{i} \ddot{\varepsilon}_{b c}^{i}+\left(\tau_{b c}^{i} \frac{\dot{k}_{b c}^{i}(\alpha, T)}{k_{b c}^{i}(\alpha, T)}\right) \dot{\varepsilon}_{b c}^{i}=\frac{\dot{\boldsymbol{\sigma}}}{k_{b c}^{i}(\alpha, T)},
$$

where the spring stiffness $k_{b c}^{i}$ and dash-pot viscosity $\tau_{b c}^{i}$ of Kelvin-Voigt units are affected by temperature and hydration degree as

$$
k_{b c}^{i}(\alpha, T)=k_{b c_{\infty}}^{i} \frac{0.473 \alpha^{0.62}}{2.081-1.608 \alpha} e^{\left(\frac{E_{a c}}{R}\left(\frac{1}{T}-\frac{1}{T_{0}}\right)\right)},
$$

and

$$
\eta_{b c}^{i}(\alpha, T)=\eta_{b c}^{i}\left(\alpha, T_{0}\right) e^{\left(\frac{E_{a c}}{R}\left(\frac{1}{T}-\frac{1}{T_{0}}\right)\right)},
$$

with the characteristic time keeping independent of the temperature

$$
\tau_{b c}^{i}=\frac{\eta_{b c}^{i}(\alpha)}{k_{b c}^{i}(\alpha)} .
$$

The creep activation energy $E_{a c}$ is often identified from experimental data, and $T_{0}=293 \mathrm{~K}$.

\section{References}

[1] A. Boumiz, C. Vernet, and F.C. Tenoudji. Mechanical properties of cement pastes and mortars at early ages: Evolution with time and degree of hydration. Advanced Cement Based Materials, 3(3-4):94-106, 1996.

[2] O. Bernard, F-J. Ulm, and E. Lemarchand. A multiscale micromechanics-hydration model for the early-age elastic properties of cement-based materials. Cement and Concrete Research, 33(9):1293-1309, 2003.

[3] D.P. Bentz. A review of early-age properties of cement-based materials. Cement and Concrete Research, 38(2):196-204, 2008.
[4] K. Kovler. Testing system for determining the mechanical behaviour of early age concrete under restrained and free uniaxial shrinkage. Materials and Structures, 27(6):324, 1994

[5] K. Kolver, S. Igarashi, and A. Bentur. Tensile creep behavior of high strength concretes at early ages. Matérials and Structures, 32(5):383-387, 1999.

[6] L. Østergaard, D.A. Lange, S.A. Altoubat, and H. Stang. Tensile basic creep of early-age concrete under constant load. Cement and Concrete Research, 31(12):1895-1899, 2001.

[7] P. Lura, K. van Breugel, and I. Maruyama. Effect of curing temperature and type of cement on early-age shrinkage of high-performance concrete. Cement and Concrete Research, 31(12):1867-1872, 2001.

[8] D. Cusson and T. Hoogeveen. Internal curing of highperformance concrete with pre-soaked fine lightweight aggregate for prevention of autogenous shrinkage cracking. Cement and Concrete Research, 38(6):757-765, 2008.

[9] A. Darquennes, S. Staquet, M-P. Delplancke-Ogletree, and B. Espion. Effect of autogenous deformation on the cracking risk of slag cement concretes. Cement and Concrete Composites, 33(3):368-379, 2011.

[10] S.H. Kwon and S.P. Shah. Prediction of early-age cracking of fiber-reinforced concrete due to restrained shrinkage. ACI Materials Journal, 105(4):381, 2008.

[11] D-Y. Yoo, J-J. Park, S-W. Kim, and Y-S. Yoon. Early age setting, shrinkage and tensile characteristics of ultra high performance fiber reinforced concrete. Construction and Building Materials, 41:427-438, 2013.

[12] D-Y Yoo, K-H. Min, J-H. Lee, and Y-S. Yoon. Shrinkage and cracking of restrained ultra-high-performance fiber-reinforced concrete slabs at early age. Construction and Building $\mathrm{Ma}$ terials, 73:357-365, 2014.

[13] S. Altoubat, K-A. Rieder, and M.T. Junaid. Short-and longterm restrained shrinkage cracking of fiber reinforced concrete composite metal decks: an experimental study. Materials and Structures, 50(2):140, 2017.

[14] D. Cusson and T. Hoogeveen. An experimental approach for the analysis of early-age behaviour of high-performance concrete structures under restrained shrinkage. Cement and Concrete Research, 37(2):200-209, 2007.

[15] M. Briffaut. Study of the early age cracking of concrete massive structures : effect of the temperature decrease rate, steel reinforcement and construction joints. Theses, École normale supérieure de Cachan - ENS Cachan, October 2010 URL https://tel . archives-ouvertes .fr/tel-00597072.

[16] K. Raoufi, J. Schlitter, D. Bentz, and J. Weiss. Parametric assessment of stress development and cracking in internally cured restrained mortars experiencing autogenous deforma- 
tions and thermal loading. Advances in Civil Engineering, 2011, 2011.

[17] M. Briffaut, F. Benboudjema, J-M. Torrenti, and G. Nahas. Concrete early age basic creep: Experiments and test of rheological modelling approaches. Construction and Building Materials, 36:373-380, 2012.

[18] I. Chu, S.H. Kwon, M.N. Amin, and J-K. Kim. Estimation of temperature effects on autogenous shrinkage of concrete by a new prediction model. Construction and Building Materials, 35:171-182, 2012.

[19] N. Shi, J. Ouyang, R. Zhang, and D. Huang. Experimental study on early-age crack of mass concrete under the controlled temperature history. Advances in Materials Science and Engineering, 2014, 2014.

[20] L. Wan, R. Wendner, and G. Cusatis. Behavior of ultrahigh-performance concrete at early age: Experiments and simulations. In First International Interactive Symposium on UHPC, 2016.

[21] L. Wan, R. Wendner, B. Liang, and G. Cusatis. Analysis of the behavior of ultra high performance concrete at early age. Cement and Concrete Composites, 74:120-135, 2016.

[22] D. Shen, J. Jiang, J. Shen, P. Yao, and G. Jiang. Influence of curing temperature on autogenous shrinkage and cracking resistance of high-performance concrete at an early age. Construction and Building Materials, 103:67-76, 2016.

[23] Z.P. Bazant. Mathematical modeling of creep and shrinkage of concrete. Wiley, 1988.

[24] F-J. Ulm and O. Coussy. Modeling of thermochemomechanical couplings of concrete at early ages. Journal of Engineering Mechanics, 121(7):785-794, 1995.

[25] G. De Schutter. Degree of hydration based kelvin model for the basic creep of early age concrete. Materials and Structures, 32(4):260, 1999.

[26] M. Cervera, J. Oliver, and T. Prato. Thermo-chemomechanical model for concrete. I: Hydration and aging. Journal of Engineering Mechanics, 125(9):1018-1027, 1999.

[27] M. Cervera, J. Oliver, and T. Prato. Thermo-chemomechanical model for concrete. II: Damage and creep. Journal of Engineering Mechanics, 125(9):1028-1039, 1999.

[28] R. de Borst and A.H. Van den Boogaard. Finite-element modeling of deformation and cracking in early-age concrete. Journal of Engineering Mechanics, 120(12):2519-2534, 1994.

[29] G. De Schutter. Finite element simulation of thermal cracking in massive hardening concrete elements using degree of hydration based material laws. Computers 8 Structures, 80 (27-30):2035-2042, 2002.

[30] Z.P. Bažant, J-K. Kim, and S-E. Jeon. Cohesive fracturing and stresses caused by hydration heat in massive concrete wall. Journal of Engineering Mechanics, 129(1):21-30, 2003.

[31] Y. Lee and J-K. Kim. Numerical analysis of the early age behavior of concrete structures with a hydration based microplane model. Computers \& Structures, 87(17-18):10851101, 2009.

[32] P. Grassl, H.S. Wong, and N.R. Buenfeld. Influence of aggregate size and volume fraction on shrinkage induced microcracking of concrete and mortar. Cement and Concrete Research, 40(1):85-93, 2010.

[33] J. Mazars. Application de la mécanique de l'endommagement au comportement non linéaire et à la rupture du béton de structure. Thèse de doctorat d'état de l'Université Paris VI, 1984.

[34] M. Briffaut, F. Benboudjema, J.M. Torrenti, and G. Nahas. Numerical analysis of the thermal active restrained shrinkage ring test to study the early age behavior of massive concrete structures. Engineering Structures, 33(4):1390-1401, 2011.

[35] M. Azenha, R. Faria, and D. Ferreira. Identification of earlyage concrete temperatures and strains: monitoring and numerical simulation. Cement and Concrete Composites, 31(6): 369-378, 2009.

[36] B. Kucharczyková, P. Daněk, D. Kocáb, and P. Misák. Experimental analysis on shrinkage and swelling in ordinary concrete. Advances in Materials Science and Engineering, 2017, 2017.

[37] M. Weiler. Investigation of crack development in a fairfaced replacement screed based on hybrid fiber-reinforced concrete. PhD thesis, University of Luxembourg, 2017.

[38] M. Kropáček and R. Čajka. Measurement of volume changes of cement concrete in large-dimensional samples. In Solid State Phenomena, volume 272, pages 102-106. Trans Tech Publ, 2018.

[39] J.H.J Kim, S.E. Jeon, and J.K. Kim. Development of new device for measuring thermal stresses. Cement and Concrete Research, 32(10):1645-1651, 2002.

[40] M.N. Amin, J-S. Kim, Y. Lee, and J-K. Kim. Simulation of the thermal stress in mass concrete using a thermal stress measuring device. Cement and Concrete Research, 39(3): 154-164, 2009.

[41] T.T. Nguyen, D. Waldmann, and T.Q. Bui. Computational chemo-thermo-mechanical coupling phase-field model for complex fracture induced by early-age shrinkage and hydration heat in cement-based materials. Computer Methods in Applied Mechanics and Engineering, 348:1-28, 2018.

[42] T.T. Nguyen, D. Waldmann, and T.Q. Bui. Phase field simulation of early-age fracture in cement-based materials. Submitted to International Journal of Mechanical Sciences, 2018.

[43] F. Benboudjema and J-M. Torrenti. Early-age behaviour of concrete nuclear containments. Nuclear engineering and design, 238(10):2495-2506, 2008.

[44] G.A. Francfort and J.J. Marigo. Revisiting brittle fracture as an energy minimization problem. Journal of the Mechanics and Physics of Solids, 46(8):1319-1342, 1998.

[45] C. Miehe, M. Hofacker, and F. Welschinger. A phase field model for rate-independent crack propagation: Robust algorithmic implementation based on operator splits. Computer Methods in Applied Mechanics and Engineering, 199:27652778, 2010.

[46] B.A. Graybeal and F. Baby. Development of direct tension test method for ultra-high-performance fiber-reinforced concrete. ACI Materials Journal, 110(2), 2013.

[47] W. Brameshuber. Recommendation of RILEM TC 232-TDT: test methods and design of textile reinforced concrete: Uniaxial tensile test: test method to determine the load bearing behavior of tensile specimens made of textile reinforced concrete. Materials and Structures, 49:4923-4927, 2016.

[48] J. Oecknick. Computergestuetzte analyse der betonerhaertung in der baupraxis. BFT, 62(10):66-72, 1996.

[49] F. Weise. Erhaertungsverlauf des betons einer bruecke. Beton, 46(12):732-734, 1996.

[50] Gebauer. Grundlagen und hinweise kintemp und kinfest.

[51] T.T. Nguyen, J. Yvonnet, Q-Z. Zhu, M. Bornert, and C. Chateau. A phase field method to simulate crack nucleation and propagation in strongly heterogeneous materials from direct imaging of their microstructure. Engineering Fracture Mechanics, 139:18-39, 2015.

[52] B. Bourdin, G.A. Francfort, and J.J. Marigo. Numerical experiments in revisited brittle fracture. Journal of the Mechanics and Physics of Solids, 48(4):797-826, 2000.

[53] B. Bourdin, G.A. Francfort, and J.J. Marigo. The variational approach to fracture. Journal of Elasticity, 91(1-3):5-148, 2008.

[54] J.A.T. de Freitas, P.T. Cuong, R. Faria, and M. Azenha. Modelling of cement hydration in concrete structures with hybrid finite elements. Finite Elements in Analysis and Design, 77:16-30, 2013.

[55] L. Stefan, F. Benboudjema, J-M. Torrenti, and B. Bissonnette. Prediction of elastic properties of cement pastes at early ages. Computational Materials Science, 47(3):775-784, 2010.

[56] R. Faria, M. Azenha, and J.A. Figueiras. Modelling of concrete at early ages: Application to an externally restrained slab. Cement and concrete composites, 28(6):572-585, 2006.

[57] L. Buffo-Lacarrière, S. Baron, F. Barré, D. Chauvel, A. Darquennes, J-P. Dubois, J. Gayete, F. Grondin, B. Kolani, H. Lançon, et al. Restrained shrinkage of massive reinforced concrete structures: results of the project ceos. fr. European Journal of Environmental and Civil Engineering, 20(7): 785-808, 2016.

[58] H. Amor, J.J. Marigo, and C. Maurini. Regularized for- 
mulation of the variational brittle fracture with unilateral contact: Numerical experiments. Journal of the Mechanics and Physics of Solids, 57(8):1209-1229, 2009.

[59] T.T. Nguyen, J. Réthoré, J. Yvonnet, and M-C. Baietto. Multi-phase-field modeling of anisotropic crack propagation for polycrystalline materials. Computational Mechanics, 60: 289-314, 2017.

[60] Waller V. and Miao B. Comportement du béton au jeune âge, chapter 6: Les paramètres influents. John Wiley \& Sons, 2004

[61] V. Waller. Relationship between mix design of concrete, generation of heat during hydration and compressive strength PhD thesis, Ecole des Ponts, 1999. URL https://hal-enpc archives-ouvertes.fr/tel-01223803

[62] A.K. Schindler. Effect of temperature on hydration of cementitious materials. Materials Journal, 101(1):72-81, 2004.

[63] P.D. Tennis, M.D.A. Thomas, and W.J. Weiss. State-of-theart report on use of limestone in cements at levels of up to 15\%. Portland Cement Association: Skokie, IL, USA, 2011.

[64] M. Azenha. Numerical Simulation of The Structural Behaviour of Concrete Since Its Early Ages. PhD thesis, Tese de Doutorado. Faculdade de Engenharia da Universidade do Porto-FEUP. Porto, 2009.

[65] P. Mounanga. Etude expérimentale du comportement de pâtes de ciment au très jeune âge: hydratation, retraits, propriétés thermophysiques. PhD thesis, Nantes, 2003.

[66] P. Laplante and C. Boulay. Evolution du coefficient de dilatation thermique du béton en fonction de sa maturité aux tout premiers âges. Materials and Structures, 27(10):596-605, 1994.

[67] M. Viviani, B. Glisic, and I.F.C Smith. Separation of thermal and autogenous deformation at varying temperatures using optical fiber sensors. Cement and Concrete Composites, 29 (6):435-447, 2007

[68] A. M. Neville. Propriétés des bétons. Paris: Eyrolles, 2000.

[69] J.R. Davis et al. ASM specialty handbook: cast irons. ASM international, 1996.

[70] M.J. Borden. Isogeometric analysis of phase-field models for dynamic brittle and ductile fracture. PhD thesis, The University of Texas at Austin, 2012.

[71] T.T. Nguyen, J. Yvonnet, M. Bornert, C. Chateau, K. Sab, R. Romani, and B. Le Roy. On the choice of parameters in the phase field method for simulating crack initiation with experimental validation. International Journal of Fracture, 197(2):213-226, 2016.

[72] T.T. Nguyen, J. Yvonnet, M. Bornert, and C. Chateau. Initiation and propagation of complex 3D networks of cracks in heterogeneous quasi-brittle materials: Direct comparison between in situ testing-microct experiments and phase field simulations. Journal of the Mechanics and Physics of Solids, 95:320 - 350, 2016. ISSN 0022-5096.

[73] S. Thelandersson. Modeling of combined thermal and mechanical action in concrete. Journal of Engineering Mechanics, 113(6):893-906, 1987

[74] A.B. Hauggaard, L. Damkilde, and P.F. Hansen. Transitional thermal creep of early age concrete. Journal of Engineering Mechanics, 125(4):458-465, 1999. 